Premio de artículos jurídicos «GARCÍA GOYENA» (Curso 2013-2014)

Premio: tercer accésit

\title{
LA TUTELA DE LAS LIBERTADES ECONÓMICAS FUNDAMENTALES EN EL PROCESO DE INTEGRACIÓN EUROPEA
}

\section{FUNDAMENTAL ECONOMIC FREEDOMS PROTECTION IN THE EUROPEAN INTEGRATION PROCESS}

\author{
JOAQUín SARRIÓN EsTEVE \\ Profesor Ayudante Doctor \\ Departamento de Derecho Constitucional, Ciencia Política y de la \\ Administración, Universitat de València. \\ joaquin.sarrion@uv.es
}

Resumen: El proceso de integración europea, en el que vivimos inmersos, reviste caracteres económicos, sociales, políticos y jurídicos; que dotan de características peculiares a un proyecto de integración cuya naturaleza está en constante discusión, casi tanto como su futuro. Sin duda, uno de los grandes protagonistas del proceso de integración ha sido y es el Tribunal de Justicia de la Unión Europea, sobre todo con la proclamación y consagración de los principios definitorios de la relación entre el ordenamiento comunitario, hoy de la Unión Europea con los ordenamientos nacionales: los principios de eficacia directa y de primacía del Derecho comunitario.

Esto lo ha hecho a la vez que desarrollaba su jurisprudencia sobre las libertades económicas fundamentales consagradas en el Tratado de la Comunidad Económica Europea (libre circulación de mercancías, libre prestación de servicios, libre circulación de trabajadores y 
libre circulación de capitales). Este trabajo tiene por objeto estudiar dicha jurisprudencia, analizando el papel preponderante de la libre circulación de mercancías, así como las perspectivas de futuro tras la entrada en vigor del Tratado de Lisboa.

Abstract: The process of European integration, in which we are immersed, has economic, social, political and legal characters giving special characteristics to an integration project whose nature is in constant discussion as its future. Certainly one of the great protagonists of the integration process has been and is the European Court of Justice, especially with the proclamation and consecration of the defining principles of the relationship between Community law, now European Union law, and national law: principles of direct effect and supremacy of EU law.

ECJ recognised this principles while it developed its jurisprudence on fundamental economic freedoms recognised in the Treaty establishing the European Economic Community (free movement of goods, freedom to provide services, free movement of workers and free movement of capitals). This work aims to study this case law, analyzing the dominant role of the free movement of goods as well as the future trends after the entry into force of Lisbon Treaty.

Palabras: Libertades económicas, Tribunal de Justicia de la Unión Europea, Derecho de la Unión Europea, Tratado de Lisboa

Words: Economic freedoms, European Court of Justice, European Union Law, Lisbon Treaty.

Sumario: 1. Introducción. 2. Mercado y libertades económicas como fundamento de la integración europea. 3. La protección de las libertades económicas. 3.1. Las libertades económicas en los tratados y el derecho derivado. 3.2. Las restricciones a las libertades económicas. el papel del Tribunal de Justicia en la tutela de las libertades económicas. 4. Conclusiones. 5. Bibliografía.

\section{INTRODUCCIÓN}

La Unión Europea (UE) ${ }^{1}$ es una realidad de la que formamos partes y cuyas características, principios y reglas desconocemos en gran medida. Ciertamente, las libertades económicas fundamentales han

${ }^{1}$ Las antiguas Comunidades Europeas han evolucionado y han terminado en lo que hoy conocemos como Unión Europea, en virtud de diferentes reformas, destacando la última llevada a cabo por el Tratado de Lisboa. 
gozado siempre de una relevancia explícita en los Tratados como instrumentos al servicio de la consecución del mercado y de la integración económica europea ${ }^{2}$.

En realidad, el proceso de integración europea, en el que vivimos inmersos, reviste caracteres económicos, sociales, políticos y jurídi$\cos ^{3}$; que dotan de características peculiares a un proyecto de integración cuya naturaleza está en constante discusión ${ }^{4}$, casi tanto como su futuro ${ }^{5}$.

Sin duda, uno de los grandes protagonistas del proceso de integración ha sido y es el Tribunal de Justicia de la Unión Europea ${ }^{6}$, sobre todo con la proclamación y consagración de los principios definitorios de la relación del ordenamiento comunitario (hoy diríamos ya Derecho de la Unión Europea) con los ordenamientos nacionales: los principios de eficacia directa y de primacía del Derecho comunitario ${ }^{7}$.

${ }^{2}$ De hecho, en esta evolución, se ha argumentado, se dejaban de lado los derechos fundamentales, y en particular los derechos sociales en un segundo lugar. Vid. PoiARES Maduro, M., "Striking the Elusive Balnce Between Economic Freedom and Social Rights in the European Union», en Alston, P., Cassese, A., Lalumière, C., LeuPRECHT, P. (eds.), An EU Human Rights Agenda for the New Millenium, Hart Publishing, Oxford, 1999, p. 449.

${ }^{3}$ Sobre la integración jurídica europea y su desarrollo no se puede dejar de citar los siguientes trabajos, a los que nos remitimos para una mayor profundización: CAPELleti, M., Seccombe, M., y WeILER, J. (eds.), Integration though law. Europe and the American Federal Experience, De Gruyter, Berlín y Nueva York, 1985; DeHousse, R., y WEILER, J., "The Dynamics of European integration: the legal dimension», en WALLACE, W. (ed.), The Dynamics of European Integration, Pinter, Londres, pp. 242-260; JoERGES, C., "Taking the Law Seriously: On Political Science and the Role of Law in the Process of European Integration», European Law Journal, n. . 2, 1996, pp. 105-135.

${ }^{4}$ Sobre la naturaleza de la Unión Europea se puede acudir a la recopilación de trabajos sobre esta cuestión del Prof. Díez Picazo, vid. Díez Picazo, L. M., La naturaleza de la Unión Europea, Civitas, 2009.

${ }^{5}$ Gillingham, J., European Integration, Cambridge University Press, Cambridge, 2003, p. xi.,

${ }^{6}$ El antaño Tribunal de Justicia de las Comunidades Europeas pasa a denominarse Tribunal de Justicia de la Unión Europea en virtud del Tratado de Lisboa.

${ }^{7}$ La relevancia de estas sentencias ha sido destacada incluso recientemente por la doctrina. Vid. los trabajos presentes en la obra Poiares Maduro, M., y Azoulai, L. (eds.), The past and Future of EU Law: The Classics of EU Law Revisited on the 50th Anniversary of the Rome Treaty, Hart Publishing, Oxford y Portland, 2010. Así por ejemplo, Pescatore, P., "Van Gend en Loos, 3 February 1963-A Vieu from Withim», pp. 3-8, que pone el acento en el surgimiento de un «new legal order» donde los sujetos ya no serían solo los Estados miembros, sino también sus nacionales, con origen en el Derecho internacional, pero desplazando el acento a la autonomía del Derecho comunitario; WitTE, B. de, "The Continuous Significance of Van Gend en Loos», pp. 9-15, que resalta la relevancia no tanto de declarar el efecto directo sino de la doctrina que asume la sentencia de que «whether specific provisions of the EEC Treaty had direct effect was to be decided centrally by the European Court of Justice itself, instead of by the various national courts according to their own views»; o si- 
Y esto lo hizo precisamente mientras desarrollaba su jurisprudencia sobre las libertades económicas fundamentales consagradas en el Tratado de la Comunidad Económica Europea (libre circulación de mercancías, libre prestación de servicios, libre circulación de trabajadores y libre circulación de capitales $)^{8}$.

Ahora bien, en el desarrollo de dicha jurisprudencia la libre circulación de mercancías tuvo un papel mayor, pues sirvió de base para el origen de dicha jurisprudencia que después influyó decisivamente en las otras libertades económicas. El objetivo de este trabajo es estudiar dicha jurisprudencia y analizar el papel preponderante de la libre circulación de mercancías, así como las perspectivas de futuro tras la entrada en vigor del Tratado de Lisboa.

guiendo en la misma obra colectiva los trabajos de MAYER, F. C., «Van Gend en Loos: The Foundation of a Community of Law», pp. 16-25; FenNelly, N., "The European Cour of Justice and the Doctrine of Supremacy: Van Gend en Loos; Costa v ENEL; Simmenthal», pp. 39-46; PERNICE, I., «Costa v ENEL and Simmentahl: Primacy of European Law», pp. 47-59; HofmanN, H. CH., "Conflicts and Integration: Revisiting Costa v ENEL and Simmenthal II», pp. 60-68; y RASMUSSEN, M., "From Costa v. ENEL to the Treaties of Rome: A Brief History of a Legal Revolution, pp.69-85.

No obstante, la separación entre ordenamiento europeo y ordenamientos nacionales es más bien formal, y cada vez más se impregnan mutuamente. Sobre esta cuestión, BORRAJO INIESTA razonaba acertadamente que «en el cielo de los conceptos, existen dos ordenamientos jurídicos distintos y separados: el Derecho comunitario, por un lado, el ordenamiento nacional, por otro (...) sin embargo, en la práctica la Constitución española se va impregnando de Derecho comunitario». Vid. su intervención «Los Tribunales constitucionales ante el Derecho comunitario. Intervención de Ignacio Borrajo Iniesta», en en Martínez de Velasco, H. H., y Zamora Zaragoza, F. J. (dir.), La articulación entre el derecho comunitario y los derechos nacionales: algunas zonas de fricción, Estudios de derecho Judicial, n. ${ }^{\circ}$ 95, CGPJ-Centro de Documentación Judicial, Madrid, 2006, p. 251.

${ }^{8}$ Dejando de lado la protección de los derechos fundamentales, que se relegó como una cuestión propia de los Tribunales constitucionales de los Estados miembros o del Tribunal Europeo de los Derechos Humanos. Sin embargo, la dinámica de la evolución del Derecho comunitario, y la relevancia de algunas sentencias de los Tribunales constitucionales de algunos Estados miembros sobre las reservas constitucionales o los contralímites motivaron que el Tribunal de Justicia asumiera la tutela de los derechos fundamentales en la Unión Europea, construyendo casuísticamente un sistema de protección de los derechos fundamentales como principios del ordenamiento comunitario. Sin embargo, es discutible que se pueda hablar, en sentido estricto, de un sistema de protección de derechos humanos en la Unión Europea, puesto que hasta la entrada en vigor del Tratado de Lisboa, el 1 de diciembre de 2009, no existía un catálogo de derechos que tuviera carácter vinculante, ni mecanismos específicos de protección de los mismos. Vid. Castillo Daudí, M., «La protección internacional de los derechos humanos en el plano regional (II): La Obra de las Comunidades Europeas y de la Unión Europea», en Bou Franch, V., y Castillo Daudí, M., Curso de Derecho Internacional de los Derechos Humanos, 2. a edición, Tirant lo Blanch, Valencia, 2010, p. 196. 


\section{EL MERCADO Y LAS LIBERTADES ECONÓMICAS COMO FUNDAMENTO DE LA INTEGRACIÓN EUROPEA}

Para conocer el origen de la integración europea debemos echar la vista atrás, y fijarnos en la conocidísima Declaración de 9 de mayo de 1950 de Schuman ${ }^{9}$. Esta declaración sentó las bases que permitieron la elaboración y aprobación de los Tratados constitutivos de las Comunidades Europeas, por parte de los Estados fundadores (Bélgica, República Federal de Alemania, Francia, Italia, Luxemburgo y los Países Bajos) ${ }^{10}$ :

- el Tratado de la Comunidad Europea del Carbón y del Acero (TCECA) de 18 de abril de $1951^{11}$;

- y los Tratados de la Comunidad Económica Europea (TCEE) y de la Comunidad Europea de la Energía Atómica (TCEEA), ambos de 27 de marzo de $1957^{12}$.

${ }^{9}$ Como es sabido la Declaración Schuman de 1950 hacía una oferta directa a Alemania para la puesta común de producciones de base (carbón y acero) que era esencial para la industria siderúrgica del momento, de tal forma que «toda guerra entre Francia y Alemania devenga no solamente impensable, sino materialmente imposible», con la institución de una Alta Autoridad, cuyas decisiones vinculen a Francia, Alemania y los demás países que se adhieran. Por tanto, había una oferta abierta para sentar las bases comunes para el desarrollo económico como primera etapa de «la Federación Europea», si bien eran conscientes de que Europa «no se hará de golpe, ni en una construcción simultánea; se hará a través de realizaciones concretas». Vid. Declaración de 9 de mayo de 1950 de Robert Schuman, http://europa.eu/abc/ symbols/9-may/decl_es.htm.

${ }^{10}$ No podemos detenernos en el estudio histórico de la formación de las Comunidades, así como su evolución histórica, se puede acudir a: GuTIÉRrez EsPADA, C., El sistema institucional de las Comunidades Europeas: de los tratados constitutivos y el Acta Única al proyecto de Tratado sobre la Unión Europea, Tecnos, Madrid, 1988; TRUYOL SERRA, A., La integración europea. Análisis histórico-documental con textos y documentos [I Génesis y desarrollo de la Comunidad Europea (1951-1979)], Tecnos, Madrid 1999; Gómez Sánchez, Y., La Unión Europea en sus documentos, Centro de Estudios Políticos y Constitucionales, Madrid, 2000; Aldecoa LuZARRAGa, F., La integración europea. Análisis histórico-institucional con textos y documentos [II Génesis y desarrollo de la Unión Europea (1979-2002), Tecnos, Madrid, 2002; CRAIG, P. y DE BURCA, G. (dir.), The Evolution of EU Law, Oxford Universtity Press, Oxford, 2008; DEDMAN, M. J., The origins and Development of the European Union (1945-2008). A History of European Integration, Routledge, 2. ${ }^{\text {a }}$ edición, Routledge, Abingdon, Oxon, 2010; ALoNso García, R., Sistema Jurídico de la Unión Europea, 2. ${ }^{a}$ edición, Thomsom-Civitas, Madrid, 2010, pp. 15-56.

${ }^{11}$ La oferta abierta de la Declaración Schuman, fue acogida, además de por Alemania, por Italia, Bélgica, Países Bajos y Luxemburgo, y las negociaciones abiertas en París en junio de 1950 cristalizaron el 18 de abril de 1951 con la firma del Tratado CECA, que entró en vigor el 25 de julio de 1952. La relevancia de la Declaración Schuman ha hecho que el 9 de mayo sea el consagrado como «El día de Europa».

${ }^{12}$ Estos dos Tratados son fruto de una iniciativa del Benelux (Bélgica, Países Bajos y Luxemburgo) presentada en la Conferencia de Messina (1955) para avanzar en 
Estos Tratados pretendían crear un mercado común ${ }^{13}$; para cuya realización efectiva eran esenciales cuatro libertades fundamentales que se subordinaban a dicho objetivo: la libre circulación de mercancías, personas, servicios y capitales ${ }^{14}$.

En 1973, se produce la primera ampliación en las Comunidades Europeas, con la adhesión del Reino Unido, Irlanda y Dinamarca. En 1981, la segunda, con la adhesión de Grecia; y en 1986 la tercera con la incorporación de España y Portugal, elevándose la cifra de miembros a 12 .

En este tiempo, en la evolución del mercado común, se habían detectado algunos problemas, y se pusieron de manifiesto en el Informe Tindemans, en 1975, que precisaba algunas reformas necesarias, pero no se llega a ningún acuerdo. Proliferan proyectos o informes sobre la reforma de las Comunidades (Informe de los Tres Sabios de 1979; el proyecto Genscher-Colombo de 1981, y el proyecto Spinelli de 1984) que no tienen éxito.

La Comisión Europea elaboró el Libro Blanco sobre la consecución del Mercado Interior ${ }^{15}$; que junto a los informes del Comité para las cuestiones institucionales de diciembre de 1984, y de marzo de 1985, sirvieron de base para aprobar el Acta Única Europea de 1986, que reformaba los Tratados constitutivos ${ }^{16}$.

Además, el Acta Única Europea (AUE) modifica la noción de «mercado común» por la de «mercado interior» para enfatizar una voluntad de unidad de mercado ${ }^{17}$.

la integración tras los fracasos de la Comunidad Europea de Defensa y de la Comunidad Política Europea.

${ }^{13}$ El art. 2 TCEE en su redacción original establecía que la misión de la Comunidad era "promover, mediante el establecimiento de un mercado común y la progresiva aproximación de las políticas económicas de los Estados miembros, un desarrollo armonioso de las actividades económicas en el conjunto de la Comunidad, una expansión continua y equilibrada, una estabilidad creciente, una elevación acelerada del nivel de vida y relaciones más estrechas entre los Estados que la integran»

${ }^{14}$ Apartados a, b, y c del art. 3 TCEE. Vid. Pérez de las Heras, B., El Mercado Interior Europeo. Las libertades económicas comunitarias: mercancías, personas, servi-

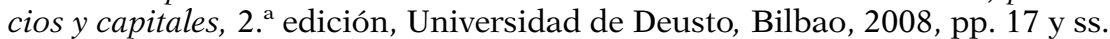

${ }^{15}$ COM (85) 310 de 9 de septiembre, presentado al Consejo en junio de 1985.

${ }^{16}$ El Acta Única Europea fue firmada en Luxemburgo el 17 de febrero de 1986, y en La Haya el 28 de febrero de 1986, entrando en vigor el 1 de julio de 1987.

${ }^{17}$ Se trataba de solventar los problemas derivados de la existencia de muchas barreras y restricciones que suponían obstáculos para la consolidación del mercado, puestos de manifiesto en el Libro Blanco sobre la consecución del Mercado Interior. Vid. PÉREZ DE las Heras, B., El Mercado Interior Europeo. Las libertades económicas comunitarias: mercancías, personas, servicios y capitales, op. cit., p. 18. 
En efecto, el nuevo concepto concretaba que se pretendía conseguir «un espacio sin fronteras interiores en el que la libre circulación de mercancías, personas, servicios y capitales estará garantiza conforme a las disposiciones del presente Tratado» ${ }^{18}$.

El AUE conduciría inexorablemente al Tratado de la Unión Europea $^{19}$. Este Tratado fue adoptado el 7 de febrero de 1992 en Maastricht, y creó la Unión Europea fundada sobre las Comunidades, y asentándose sobre el acervo comunitario ${ }^{20}$.

El art. 2 TCE tal y como se modifica, establece que se pretende conseguir «un desarrollo armonioso y equilibrado de las actividades económicas en el conjunto de la Comunidad, un crecimiento sostenible y no inflacionista que respete el medio ambiente, un alto grado de convergencia social, la elevación del nivel y de la calidad de vida, la cohesión económica y social y la solidaridad entre los Estados miembros»; y establece en el arts. 3 y 4 TCE como instrumentos necesarios para los mismos el establecimiento de un mercado común y de una unión económica y monetaria ${ }^{21}$.

Al mismo tiempo, el preámbulo del TUE proclamaba la adhesión de los Estados miembros al principio de respeto de los derechos humanos y de las libertades fundamentales; y el compromiso de la Unión Europea de respetar los derechos fundamentales tal y como se garantizan en el Convenio Europeo para la protección de los derechos humanos y las libertades fundamentales.

En 1995, se produce una nueva ampliación, con la incorporación de tres Estados miembros: Suecia, Finlandia y Austria ${ }^{22}$.

LIDFELDT considera que el cambio del término de «from that of common market to internal market has in practise had little effect and they are likey to be understood as synonymous concepts». Vid. LINDFELT, M., Fundamental Rights in the European Union - Towards Higher Law of the Land? A Study of the Status of Fundamental Rights in a Broader Constitutional Setting, Åbo Akademi University, Åbo, 2007, p. 188.

${ }^{18}$ Art. 8. ${ }^{a}$ párrafo segundo del TCEE introducido por el AUE. Sobre esta evolución, vid. Mortelmans, K., «The Common Market, the Internal Market and the Single Market, what's in a market?, Common Market Law Review, v. 35, n. ${ }^{\circ}$ 1, 1998, pp. 101-136.

${ }^{19}$ Mangas Martín, A., Liñán Nogueras, D. J., Instituciones y Derecho de la Unión Europea, 1. ${ }^{\text {a }}$ edición, McGraw-hill, Madrid, 1996, p. 25.

${ }^{20}$ Ídem, p. 26.

El Tratado de la Unión Europea se firma en Maastricht el 7 de febrero de 1992, y entró en vigor el 1 de noviembre del año siguiente.

${ }^{21}$ La unión económica y monetaria se erige en «el complemento indispensable de la consolidación del mercado interior». Vid. PÉREz DE LAS HeRAS, B., El Mercado Interior Europeo. Las libertades económicas comunitarias: mercancías, personas, servicios y capitales, op. cit., pp. 19-20.

${ }_{22}$ También estaba prevista la incorporación de Noruega, pero el referéndum para la adhesión tuvo un resultado negativo. 
Un año más tarde, sería la Conferencia Intergubernamental de 1996 la que trataría de dar un nuevo impulso a la integración, origen del Tratado de Ámsterdam ${ }^{23}$. Este Tratado introduce en el art. 2 TCE como nuevos objetivos «la igualdad entre el hombre y la mujer» $\mathrm{y}$ «un alto grado de competitividad».

Además, establece una norma que vincula la UE a los Derechos Humanos, disponiendo que se basaría en los principios de libertad, democracia, respeto de los derechos humanos y las libertades fundamentales, y mantenía su compromiso con el respeto de los derechos consagrados por el $\mathrm{CEDH}^{24}$. También modificaba el TCE, disponiendo que la política comunitaria en el ámbito de la cooperación al desarrollo contribuiría al objetivo de respeto de los derechos humanos y libertades fundamentales ${ }^{25}$.

Posteriormente, es importante detenernos un momento en el Consejo de Niza. Esta reunión culmina con el Tratado de Niza ${ }^{26}$, que deja intactos los objetivos previstos en el art. 2 TCE, y las acciones previstas en los arts. 3 y 4 del mismo, relativas a la consecución del mercado y de la unión económica y monetaria ${ }^{27}$.

$\mathrm{Al}$ mismo tiempo, introduce pequeñas modificaciones en materia de derechos humanos, en el Tratado de la Unión Europea ${ }^{28}$, y en Tratado de la Comunidad Europea ${ }^{29}$.

Sin embargo, el Consejo de Niza es relevante, porque en su seno se adoptó la Carta de los Derechos Fundamentales de la Unión Europea, a través de una Declaración de la Comisión Europea, el Parlamento Europeo y el Consejo de 7 de diciembre de $2000^{30}$.

${ }^{23}$ Mangas Martín, A., LiÑán Nogueras, D. J., Instituciones y Derecho de la Unión Europea, 6. ${ }^{\text {a }}$ edición, Tecnos, Madrid, 2010, pp. 39 y 40. El Tratado de Ámsterdam se firma en Luxemburgo el 2 de octubre de 1997, y entra en vigor el 1 de mayo de 1999.

${ }^{24}$ Art. 6.1 y 2 Tratado de la Unión Europea.

${ }^{25}$ Art. 177. 2 TCE.

${ }^{26}$ El Tratado de Niza, se firma el 26 de febrero de 2001 en la ciudad de Niza, y entra en vigor el 1 de febrero de 2003.

${ }^{27} \mathrm{Al}$ respecto vid. PÉREz de las Heras, B., El Mercado Interior Europeo. Las libertades económicas comunitarias: mercancías, personas, servicios y capitales, op. cit., p. 19 , nota 6 .

${ }^{28}$ Quizá cabe destacar la introducción de un mecanismo de carácter preventivo para el procedimiento del art. 7 TUE. Vid. Keller, H., y SchNell, C., «International Human Rights Standards in the EU - A Tightrope Walk between Reception and Parochialism?», Swiss Review of International and European Law, n. ${ }^{\circ}$ 1, 2010, p. 7.

${ }^{29}$ Castillo Daudí, M., "Los derechos humanos en la Unión Europea», Cuadernos de Integración Europea, n. ${ }^{\circ}$ 4, 2006, p. 26.

${ }^{30}$ La forma que optó por adoptar fue la de una Declaración de la Comisión Europea, el Parlamento Europeo y el Consejo. Esta carta fue publicada en el DOCE de 18 de diciembre de 2000, 1 Serie C, C-364/01. 
Además, el Acta Final del Tratado de Niza llevaba aneja una Declaración sobre el futuro de la Unión, donde se solicitaba un debate amplio y profundo sobre el desarrollo futuro de la Unión Europea, y que permitió la apertura de un proceso de debate. En Diciembre de 2001, el Consejo Europeo acordó la llamada Declaración de Laeken para impulsar el proceso, y acordó la constitución de una Convención, que comenzó los trabajos el 28 de febrero de 2002 para preparar un proyecto de reforma de los Tratados. La Convención sobre el futuro de Europa concluiría en un «Proyecto de Tratado por el que se instituye una Constitución para Europa», presentado al Presidente del Consejo Europeo en Roma, el 18 de julio de $2003^{31}$.

A la Conferencia Intergubernamental que trabajó sobre dicho proyecto, se invitó a los países candidatos que hubieran terminado sus negociaciones de adhesión, así como también en calidad de observadores, a aquellos Estados candidatos que no las hubieran concluido. Dicha Conferencia comenzó a trabajar, y sin que se llegaran a aprobar una reforma, se produjo la adhesión prevista de 10 nuevos Estados miembros, el 1 de mayo de 2004: Estonia, Letonia, Lituania, Polonia, República Checa, Eslovaquia, Hungría, Eslovenia, Chipre y Malta.

El 18 de junio de 2004, los Jefes de Estado y de Gobierno de los 25 Estados miembros aprobaron el Proyecto de Tratado por el que se establece una Constitución para Europa, que incorporaba la Carta de Derechos Fundamentales adaptada para su inclusión en el mismo (Parte II, arts. II-61-114). No obstante, no llegaría a entrar en vigor, pues tras el rechazo en los referéndums francés y holandés, muchos otros Estados miembros mostraron su rechazo al proyecto ${ }^{32}$.

Tras dicho fracaso, se inició un largo periodo de incertidumbre sobre el futuro de la reforma, que no excluyó que hubiera una nueva ampliación, con la adhesión de Rumanía y Bulgaria el 1 de enero de 2007.

Finalmente, la Declaración de Berlín de 25 de marzo de 2007 dejó claro que se no había posibilidad de seguir con el proyecto de Tratado constitucional. Posteriormente, el Consejo Europeo de 21 y 22 de junio

${ }^{31}$ Sobre la Convención, vid. RoIg MolÉs, E., «Continuidad y refundación; deliberación y decisión: el proceso de la Convención y la reforma de los Tratados», en ALBerti Rovira, A. (dir.), El Proyecto de nueva Constitución Europea, Tirant lo blanch,, Valencia, 2004, pp. 17-131; Calonge Velázouez, A., «Preparación y elaboración de la Constitución para Europa: la Convención sobre el futuro de Europa», Revista de Derecho de la Unión Europea, n. ${ }^{\circ}$ 8, 2005, pp. 53-70.

${ }^{32}$ Mangas Martín, A., «Introducción. El Compromiso con los derechos fundamentales», en Mangas Martín, A. (ed.), Carta de los derechos fundamentales de la Unión Europea: comentario artículo por artículo, Fundación BBVA, Bilbao, 2008, p. 64. 
de 2007, convocó una nueva Conferencia Intergubernamental para reformar los Tratados, pero según un mandato preciso. Y en la Cumbre de Lisboa, que se celebró los días 18 y 19 de octubre, se acordó el Tratado de Reforma de los Tratados constitutivos, denominado Tratado de Lisboa, que se firma el 13 de diciembre en la capital portuguesa ${ }^{33}$.

Por otro lado, se adaptó y actualizó el texto de la Carta de los Derechos Fundamentales de la Unión Europea, eliminando las adaptaciones que se había hecho para su inclusión en el proyecto de Tratado constitucional, proclamándose de forma solemne en Estrasburgo el 12 de diciembre de 2007, un día antes de la firma del Tratado de Lisboa ${ }^{34}$.

El Tratado de Lisboa recoge buena parte del proyecto de Tratado constitucional $^{35}$; si bien a diferencia del antedicho proyecto no supone un Tratado sustitutivo de los Tratados constitutivos, sino una modificación de los mismos, afectando tanto al TUE, el TCE, y el TCEEA ${ }^{36}$.

En este sentido, atribuye a la Unión Europea personalidad jurídica de forma expresa, sucediendo a la Comunidad Europea. El Tratado

33 Ídem.

${ }^{34}$ Esta versión de la Carta fue aprobada por el Parlamento europeo el 29 de noviembre de 2007 (P6_TA-prov(2007)0573, A6-0445(2007)), y proclamada y firmada por las tres instituciones, el 12 de diciembre de 2007.

http://europa.eu/rapid/pressReleasesAction.do?reference=IP/07/1916\&format=HT ML\&aged $=1$ \&language $=$ ES\&guiLanguage $=$ en

Se publica en el Diario Oficial el 14 de diciembre de 2007 (DOUE C 303/01 de 14 de diciembre de 2007).

El hecho de que fuera proclamada de forma solemne en Estrasburgo, el 12 de diciembre, ha motivado que algunos autores se refieran a ella como Carta de Estrasburgo, en contraposición a la versión de Niza. Vid. PAGANo, E., «Dalla Carta di Nizza alla Carta di Strasburgo dei diritti fondamentali», Diritto Pubblico Comparato ed Europeo, n. ${ }^{\circ}$ 1, 2008, www.dpce.it; PARISI, N., «Funzione e ruolo della Carta dei diritti fondamentali dell'Unione europea nel sistema delle fonti alla luce del Trattato di Lisbona», www.estig.ipbeja.pt/ ac_direito/FunzioneCarta_dei_diritti_fondamentali.pdf, p. 16.

${ }^{35}$ Así, del proyecto de Tratado constitucional se mantienen: la simplificación de la estructura jurídica mediante la extinción de la Comunidad Europea, las innovaciones institucionales como la Presidencia permanente del Consejo Europeo, la creación de un representante exterior e la Unión, la fórmula de la doble mayoría para la votación del Consejo por mayoría cualificada, la eficacia jurídica de la Carta (aunque mediante referencia y no incluyéndola en el texto), un mayor protagonismo al Parlamento Europeo con la extensión del procedo de codecisión, la introducción de un mecanismo de participación de los Parlamentos nacionales para la tutela y el respeto del principio de subsidiariedad; la iniciativa legislativa popular, la posibilidad de que un Estado miembro se retire de la Unión, etc. Se pierde cierta claridad, la inclusión del principio de primacía del Derecho comunitario, la simbología «constitucional» que tenía el Tratado.

${ }^{36}$ Respecto al TCEEA o también conocido como Tratado del Euratom, es el Protocolo n..$^{\circ}$ al Tratado de Lisboa el que modifica el mismo, con unas breves tres páginas, parece que dedicadas a retocar el TCEEA para adecuarlo a las modificaciones introducidas por el Tratado de Lisboa en los otros Tratados. 
de la Unión Europea (TUE) mantiene su denominación, pero el Tratado de la Comunidad Europea pasa a denominarse Tratado de Funcionamiento de la Unión Europea (TFUE).

El actual art. 3 del TUE proclama los objetivos de la Unión, y en su apartado tercero se dispone que:

«La Unión establecerá un mercado interior. Obrará en pro del desarrollo sostenible de Europa basado en un crecimiento económico equilibrado y en la estabilidad de los precios, en una economía social de mercado altamente competitiva, tendente al pleno empleo y al progreso social, y en un nivel elevado de protección y mejora de la calidad del medio ambiente. Asimismo, promoverá el progreso científico y técnico.

La Unión combatirá la exclusión social y la discriminación y fomentará la justicia y la protección sociales, la igualdad entre mujeres y hombres, la solidaridad entre las generaciones y la protección de los derechos del niño.

La Unión fomentará la cohesión económica, social y territorial y la solidaridad entre los Estados miembros.

La Unión respetará la riqueza de su diversidad cultural y lingüistica y velará por la conservación y el desarrollo del patrimonio cultural europeo.»

Y el art. 2 TUE añade:

«La Unión se fundamenta en los valores de respeto de la dignidad humana, libertad, democracia, igualdad, Estado de Derecho y respeto de los derechos humanos, incluidos los derechos de las personas pertenecientes a minorías. Estos valores son comunes a los Estados miembros en una sociedad caracterizada por el pluralismo, la no discriminación, la tolerancia, la justicia, la solidaridad y la igualdad entre mujeres y hombres.»

No es menos relevante el hecho de que el TUE atribuye fuerza jurídica a la Carta de los Derechos Fundamentales de la Unión Europea, en el art. 6.1 TUE en la versión de la misma proclamada el 12 de diciembre de $2007^{37}$.

En resumen, el «mercado» ha constituido el corazón de la construcción sustancial de las Comunidades y de la Unión Europea; como fundamento e instrumento clave en la evolución del orden jurídico europeo junto a las libertades económicas que lo sustentan ${ }^{38}$.

${ }^{37}$ Como hemos indicado con antelación, algunos autores han aprovechado para llamar a esta versión la Carta de Estrasburgo. Vid. PAGANo, E., «Dalla Carta di Nizza alla Carta di Strasburgo dei diritti fondamentali», op. cit., PARISI, N., "Funzione e ruolo della Carta dei diritti fondamentali dell'Unione europea nel sistema delle fonti alla luce del Trattato di Lisbona», op. cit., p. 16.

${ }^{38}$ De hecho, se ha hablado del Mercado como corazón de la constitución sustantiva o material de la Comunidad. Así, WEILER razona que «The common market, the 
Pero no es menos cierto que de forma progresiva los derechos fundamentales y su protección han ido ganando una mayor significación y relevancia. Así, desde el silencio que sobre los mismos guardaban los Tratados Constitutivos, ha existido un largo proceso que ha culminado en la atribución de fuerza jurídica a una Carta de Derechos Fundamentales, plenamente vigente desde la entrada en vigor del Tratado de Lisboa el 1 de diciembre de $2009^{39}$.

\section{LA PROTECCIÓN DE LAS LIBERTADES ECONÓMICAS}

\subsection{Las libertades económicas en los tratados y el derecho derivado}

Las cuatro libertades económicas fundamentales han gozado desde el principio de un lugar privilegiado y es que el sistema instaurado por el TCEE estaba basado fundamentalmente en la consecución de mercado comunitario, por lo que las consideraciones de carácter social eran de una relevancia secundaria respecto a las libertades económicas ${ }^{40}$.

heart of the material or substantive constitution of the Community, was in large measure judicially "constituted" and is, too, an important part of overall European constitutionalism»Vid. WeILER, J. H. H., «The Constitution of the common Market Place: Text and Context in the Evolution of the Free Movement of Goods», en CRAIG, P., DE BúrcA, G. (eds.), The Evolution of EU Law, Oxford University Press, Oxford,1999, pp. 349-376. Incluso se ha llegado a afirmar que dicho Mercado constituiría el corazón de una "constitución económica», vid. CASSESE, S., "La costituzione economica europea», Revista Italiana di Diritto Pubblico comunitario, n. ${ }^{\circ}$ 6, 2008, pp. 907 y ss.; Maestro Buelga, G., «El Tratado de Lisboa y la Constitución económica», Revista de Derecho Constitucional Europeo, n. ${ }^{\circ}$ 9, 2008, pp. 37-68. En el mismo sentido, refiriéndose a la relevancia de las cuatro libertades y la «constitución económica», vid. ConsTANTINESCO, V., "La constitution économique de la CEE», Revue Trimestrielle de droit européen, n. ${ }^{\circ}$ 2, 1977, p. 244; BAQUERO CRUZ, J., Entre competencia y libre circulación. El Derecho constitucional económico de la Comunidad Europea, Civitas, Madrid, 2002; y Calvano, R., La Corte di giustizia e la costituzione europea, Cedam, Padova, 2004.

Se puede ver una excelente reflexión sobre lo que ha supuesto el mercado en la Unión en JACOBS, F. G, "The evolution of the European Legal Order», Common Market Law Review, v. 41, n. ${ }^{\circ} 2$, 2004, pp. 303-316. En efecto, este autor considera al Mercado como algo fundamental en la evolución del orden legal europeo, llegando a calificarlo como «the key concept» incluso en la actualidad, p. 304. Por otro lado, el propio Tribunal de Justicia definió el mercado común (Sentencia de 5 de mayo de 1982, Gaston Schul c. Inspector der Invoerrechten, asunto C-15/81, apartado 33).

${ }^{39}$ Esto ha abierto un nuevo «horizonte constitucional» en la UE. Sobre esta cuestión, permítaseme remitir a mi trabajo: «El nuevo horizonte constitucional para la Unión Europea: a propósito de la entrada en vigor del Tratado de Lisboa y la Carta de Derechos Fundamentales», CEFLegal: revista práctica de derecho, n. ${ }^{\circ}$ 121, 2011, pp. 53-102.

${ }^{40}$ Vid. el trabajo de Poiares Maduro, M., «Striking the Elusive Balance Between Economic Freedom and Social Rights in the EU», op cit. En el mismo sentido, LIN- 
Las cuatro libertades constituyen por tanto el fundamento del mercado (art. 26.2 TFUE) y están reguladas sustancialmente ${ }^{41}$ :

1. la libre circulación de mercancías se encuentra regulada en los arts. 28-37 TFUE ${ }^{42}$; siendo importante destacar también el Reglamento (CE) 2679/98 del Consejo, de 7 de diciembre de 1998, sobre el funcionamiento del mercado interior en relación con la libre circu-

DFELT, M., Fundamental Rights in the European Union - Towards Higher Law of the Land? A Study of the Status of Fundamental Rights in a Broader Constitutional Setting, op. cit., pp. 185 y ss. Por esa razón algunos autores les han atribuido el status de «super derechos». Al respecto vid. HELISKOSKI, J., «Fundamental Rights versus Economic Freedoms in the European Union: Which paradigm?», en Petman, J., KlabBers, H. (eds.), Nordic Cosmopolitanism: Essays in International Law for Martti Koskenniemi, Martinus Nijhoff Publishing, Leiden, 2004, pp. 417-443.

${ }^{41}$ Antes regulado en el art. 3 TCE.

Hay que decir que las cuatro libertades, además de una regulación básica en los Tratados, han gozado de desarrollo legislativo a través del Derecho derivado. Nos limitamos a citar las disposiciones más relevantes puesto que hay un gran número de disposiciones que les afectan y hacer mención de todas ellas excedería de los límites e interés para este trabajo de investigación. A estos efectos se puede acceder a toda la legislación el mercado interior y las cuatro libertades en http://europa.eu/legislation_summaries/internal_market/index_es.htm.

No obstante, destacamos afectando en general a las libertades: la Directiva 2004/18/CE del Parlamento Europeo y del Consejo, de 31 de marzo de 2004, sobre coordinación de los procedimientos de adjudicación de los contratos públicos de obras, de suministro y de servicios; [DO L134 30.4.2004], modificada por la Directiva 2005/75/CE [DO L323 9.12.2005], el Reglamento (CE) n. ${ }^{\circ}$ 2083/2005 [DO L333 20.12.2005]; Directiva 2006/97/CE [DO L363 20.12.2006]; Reglamento (CE) n. ${ }^{\circ}$ 1422/2007 [DO L317 5.12.2007]; Directiva 2009/81/CE [DO L216 20.8.2009]; y el Reglamento (CE) n. ${ }^{\circ} 1177 / 2009$ [DO L315 1.12.2009].

Para un estudio de las cuatro libertades seguimos esencialmente los estudios de Barnard, C., y SCOTt, J. (eds), The Law of the Single European Market, Hart Publishing, 2002; DAVIES, G., European Union Internal market Law, Cavendish Publishing, Londres, 2002; BARNARD, C., The substantive law of the EU, The four freedoms, Oxford University Press, Oxford, 2007; y PÉREz de LAs Heras, B., El Mercado Interior Europeo. Las libertades económicas comunitarias: mercancías, personas, servicios y capitales, op. cit.

${ }^{42}$ La libre circulación de mercancías se regula de forma específica en dicho Título II de la Tercera Parte del TFUE, en los arts. 28-37. Los arts. 28.1 y 30 TFUE (antiguos arts. 23 a 31 del Título I de la Tercera Parte del TCE) prohíben los derechos de aduana y las exacciones de efecto equivalente; los arts. 34 a 36 TFUE (antiguos arts. 28 a 30 TCE) establecen la supresión de las restricciones cuantitativas y las medidas de efecto equivalente; y el art. 37 (antiguo art. 31 TCE) regula la adecuación de los monopolios nacionales de carácter comercial; finalmente, el art. 110 TFUE (antiguo art. 90 TCE) de forma separada regula la supresión de los impuestos internos de carácter discriminatorio y protector.

Para un estudio de la regulación específica de esta libertad vid. Oliver, P., Free movements of goods in the European Community, Sweet \& Maxwell, Londres, 1996; GormLEY, L. W., EU Law of Free Movement of Goods and Customs Union, Oxford University Press, Oxford, 2008; y PÉREZ DE las Heras, B., El Mercado Interior Europeo. Las libertades económicas comunitarias: mercancías, personas, servicios y capitales, op. cit., pp. 23-82. 
lación de mercancías entre los Estados miembros, por el que se establece un nuevo mecanismo de intervención para asegurar la libre circulación de mercancías en situaciones conflictivas ${ }^{43}$.

2. la libre circulación de personas-trabajadores, está regulada en los arts. 45 a 48 TFUE $^{44}$, y en el Reglamento CEE 1612/68 de 15 de octubre de $1968^{45}$;

Se ha destacado que la libre circulación de trabajadores queda "funcionalizada» y reconducida a la libre prestación de servicios, lo que se ha dicho es una muestra de subordinación del trabajo al mercado $^{46}$; sin perjuicio de que quizá ha sido más relevante su evolución hacia la libre circulación de personas ${ }^{47}$.

43 [Diario Oficial L 337 de 12.12.1998] Este Reglamento permite a la Comisión solicitar a través de una notificación al Estado mimbro que adopte las medidas necesarias para eliminar un obstáculo que sea manifiesto y específico respeto a la libre circulación de mercancías, estando previsto que en caso de que no lleve a cabo esta eliminación del obstáculo, la Comisión podría enviar un dictamen motivado (que está previsto y regulado en el art. 258 TFUE, antiguo art. 226 TCE). Sobre este mecanismo vid. GonZÁlez VAQuÉ, L., «El nuevo mecanismo de intervención para asegurar la libre circulación de mercancías en situaciones conflictivas», Gaceta Jurídica de la CE, B-128, 1997, pp. 17-24; y MATTERA, A., «El Reglamento n. ${ }^{\circ}$ 2679/98: un instrumento de intervención rápida para salvaguardar la unidad de Mercado Interior», Gaceta Jurídica de la Unión Europea y de la competencia, n. $.^{\circ} 204,1999$, pp. 21-35.

También es relevante el Reglamento (CE) n. ${ }^{\circ}$ 764/2008 del Parlamento Europeo y del Consejo, de 9 de julio de 2008, por el que se establecen procedimientos relativos a la aplicación de determinadas normas técnicas nacionales a los productos comercializados legalmente en otro Estado miembro y se deroga la Decisión n. . 3052/95/ CE; Esta Decisión que queda derogada establecía el procedimiento de «información mutua sobre las medidas nacionales de excepcional principio de libre circulación de mercancías en la Comunidad».

${ }^{44}$ Antiguos arts. 39 a 42 TCE. Se trata de una libertad de movilidad de personas, nacionales de los Estados miembros que se desplazan a otros Estados miembros para trabajar por cuenta ajena, inspirándose en el principio de igualdad de trato o de no discriminación por razón de nacionalidad respecto de los trabajadores nacionales de los Estados miembros.

Para un estudio de la regulación específica, vid. PÉREz DE LAS Heras, B., El Mercado Interior Europeo. Las libertades económicas comunitarias: mercancías, personas, servicios y capitales, op. cit., pp. 83-120

45 [DO L257 de 19 de octubre de 1968]. Este Reglamento ha sido objeto de numerosas modificaciones: Reglamento (CEE) n. ${ }^{\circ}$ 1612/68 del Consejo [DO L 39 de 14.2.1976]; Reglamento (CEE) n. ${ }^{\circ}$ 2434/92 del Consejo [DO L245 de 26.8.1992]; Directiva 2004/38/CE del Parlamento Europeo y del Consejo [DO L158 de 20.4.2004].

${ }^{46} \mathrm{Vid}$. en este sentido Lo FARO, A., «Diritti sociali e libertà economiche del mercato interno: considerazioni minime in margine ai casi Laval e Viking», Lavoro e diritto, v. 22., n. ${ }^{\circ}$ 1, 2008, pp. 63-98; Patruno, L., "Il Caso Rúffert: la Corte di giustizia CE fa un altro passo avanti nella "via giudiziaria al dumping sociale» accesible en www. costituzionalismo.it.

${ }^{47}$ Vid. Castro OliveIRa, A., «Workers and other persons: step-by-step from movement to citizenship», Common Market Law Review, v. 39, n. ${ }^{\circ}$ 1, 2002, pp. 77-127. Sobre la importancia de esta libertad y en particular su contribución a la construcción de la ciuda- 
3. la libre circulación de servicios, que está conformada por el derecho de establecimiento, regulado en los arts. 49-54 TFUE ${ }^{48}$; y la libre prestación de servicios, prevista en los arts. 56-62 TFUE, siendo relevantes las Directivas 2006/123/CE de 12 de diciembre de 2006 relativa a los servicios en el mercado interior ${ }^{49}$; la Directiva 96/71/CE del Parlamento Europeo y del Consejo de 16 de diciembre de 1996 sobre el desplazamiento de trabajadores efectuado en el marco de una prestación de servicios $^{50}$; la Directiva 2004/113/CE del Consejo, de 13 de diciembre de 2004, por la que se aplica el principio de igualdad de trato entre hombres y mujeres en el acceso a bienes y servicios y suministro ${ }^{51}$; la Directiva 2005/36/CE del Parlamento Europeo y del Consejo, de 7 de septiembre de 2005, relativa al reconocimiento de cualificaciones profesionales ${ }^{52}$;

4. la libre circulación de capitales, que contempla la libre circulación de capital y pagos, está regulada en los arts. 63-65, y $75 \mathrm{TFUE}^{53}$. Se trata de la libertad que más ha tardado en desarrollarse, pero probablemente la que ha alcanzado un desa-

danía europea, vease mi contribución y otros trabajos de la obra BENLLOCH DoMÈNECH, C. (Dir), Construyendo ciudadanía europea a través de las TICs, Comares, 2009. Mi último trabajo sobre el tema: «La libre circulación de personas como dereho fundamental de los ciudadanos en la Unión Europea», Panorama Social, n. ${ }^{\circ} 17,2013$, pp. 33-40.

${ }^{48}$ Estamos hablando de dos conceptos, por un lado el derecho de establecimiento, regulado en los arts. 49.54 TFUE (antiguos arts. 43-48 TCE) y de la libre prestación de servicios, regulado en los arts. 56-62 TFUE (antiguos arts. 49-54 TCE). Sin embargo, como libertades personales referidas a los trabajadores autónomos el art. 62 TFUE (antiguo art. 55 TCE) establece una conexión entre ellas, estableciendo que " Las disposiciones de los arts. 45 a 48 inclusive son aplicables al ámbito regulado por el presente capítulo». Para un estudio específico de esta libertad, vid. PÉREZ DE LAS Heras, B., El Mercado Interior Europeo. Las libertades económicas comunitarias: mercancías, personas, servicios y capitales, op. cit., pp. 120-151.

${ }^{49}$ En cuanto al Derecho derivado hay que tener en cuenta la Directiva 2006/123/ CE de 12 de diciembre de 2006 relativa a los servicios en el mercado interior [DOUE L 376 de 27 de diciembre de 2006] conocida popularmente como la Directiva «Bolkestein», cuyo plazo límite de incorporación en los estados miembros era el 28 de diciembre de 2009.

50 [DO L18 21.1.1997]

51 [DO L373 21.12.2004]

52 [DO L255 30.9.2005] modificada por la Directiva 2006/100/CE [DO 363 20.12.2006], y el Reglamento (CE) n. ${ }^{\circ}$ 1127/2008 [DO L311 21.11.2008]

${ }^{53}$ Efectivamente, esta libertad se encuentra regulada en los arts. 63-65, y 75 TFUE (antiguos arts. 56-60 TCE).

Para un estudio específico de esta libertad y la evolución y desarrollo de la misma vid. PÉRez de las Heras, B., El Mercado Interior Europeo. Las libertades económicas comunitarias: mercancías, personas, servicios y capitales, op. cit., pp. 185-204; HINOJO$\mathrm{SA}, \mathrm{L}$. M., La regulación de los movimientos internacionales de capital desde una perspectiva de europea, Mc Graw Hill, Madrid, 1999. 
rrollo más pleno ${ }^{54}$. Cabe destacar, entre otras, la Directiva 2007/64/CE de 13 de noviembre de 2007, sobre servicios de pago en el mercado interior ${ }^{55}$.

En el régimen jurídico de las libertades económicas fundamentales siempre se ha previsto la prohibición de restricciones a las mismas, pero no de forma absoluta, permitiéndose restricciones que estuvieran justificadas.

Así, para garantizar la efectividad de la libre circulación de mercancías se prohíbe en los intercambios de mercancías entre los Estados miembros la aplicación de derechos de aduana y de otras tasas o exacciones de efecto equivalente en los arts. 28.1 y 30 TFUE (antiguos arts. 23 y $25 \mathrm{TCE}$ ); prohíben como obstáculos en los intercambios comerciales intracomunitarios las restricciones cuantitativas y las medidas de efecto equivalente en los arts. 34 y 35 TFUE (ex arts. 28 y 29 TCE) $)^{56}$; se exige que se adecúen los monopolios nacionales de

${ }^{54}$ En este sentido, Pérez de las Heras, B., El Mercado Interior Europeo. Las libertades económicas comunitarias: mercancías, personas, servicios y capitales, op. cit., pp. 185-204.

La libre circulación de capitales se desarrollo a través de las Directivas de 11 de mayo de 1960 [JOCE n. ${ }^{\circ} 43$ de 14 de julio de 1960], y Directiva 63/21/CEE DE 18 de diciembre de 1962 [JOCE n. ${ }^{\circ} 9$, de 22 de enero de 1963] que permanecieron hasta la reforma llevada a cabo por la Directiva 85/583/CEE.

55 [DOUE L319 de 5 de diciembre de 2007]; por supuesto, también son destacables la Directiva 2005/60/CE de 26 de octubre de 2005, relativa a la prevención de la utilización del sistema financiero para el blanqueo de capitales y para la financiación del terrorismo [DOUE L309 de 25 de noviembre de 2005]; el Reglamento (CE) 1889/2005 de 26 de octubre de 2005, relativo a los controles de la entrada o salida de dinero efectivo de la Comunidad [DOUE L309 de 25 de noviembre de 2005]; la Directiva 2003/48/CE de 3 de junio de 2003 en materia de fiscalidad de los rendimientos del ahorro en forma de pago de intereses. [DOUE L157 de 26 de junio de 2003]; también hay que tener en cuenta la Directiva 2001/86/CE, de 8 de octubre de 2001, por la que se completa el estatuto de la Sociedad Anónima Europea en lo que respecta a la implicación de los trabajadores. [DO 1294 de 10.11.2001]; y la Directiva 98/27/CE del Parlamento Europeo y del Consejo de 19 de mayo de 1998 relativa a las acciones de cesación en materia de protección de los intereses de los consumidores [DO L 166 de 11.6.1998].

${ }^{56}$ Si bien el concepto de derecho de aduna no ha planteado problemas, sí lo ha hecho el de tasas o exacciones de efecto equivalente, siendo resuelto por la jurisprudencia del Tribunal de Justicia, que en la Sentencia de 14 de diciembre de 1962, Comisión c. Gran Ducado de Luxemburgo y Reino de Bélgica, asuntos C-2 y 3/62, consideró que constituían exacciones de efecto equivalente los derechos que gravaban en Bélgica y Luxemburgo gravan la expedición de licencias para importar determinados tipo s de productos, entendiendo que «toda carga pecuniaria, que no constituye propiamente un derecho de aduana, que es unilateralmente impuesta por un Estado miembro, ya sea en el momento de su importación o posteriormente, y que grava exclusivamente el producto importado de otro Estado miembro: alterar el precio de reventa de la mercancía importada, ese gravamen produce el mismo efecto que un 
carácter comercial en el art. 37 TFUE (antiguo art. $31 \mathrm{TCE})^{57}$; se prohíben las restricciones derivadas de disposiciones nacionales sobre impuestos indirectos en el art. 110 TFUE (antiguo art. 90 TCE); y los arts. 34 a 36 TFUE (antiguos arts. 28 a 30 TCE) ; $^{58}$

Lo que nos interesa resaltar es que si bien se prohíben las restricciones cuantitativas y las medidas de efecto equivalente como obstáculos (arts. 34 y 35 TFUE), el 36 TFUE (ex art.30 TCE) prevé la posibilidad de establecer "prohibiciones o restricciones a la importación, exportación o tránsito justificadas por razones de orden público, moralidad y seguridad públicas, protección de la salud y vida de las personas y animales, preservación de los vegetales, protección del patrimonio artístico, histórico o arqueológico nacional o protección de la propiedad industrial y comercial». Teniendo en cuenta que «tales prohibiciones o restricciones no deberán constituir un medio de discriminación arbitraria ni una restricción encubierta del comercio entre los Estados miembros».

En relación a la libre circulación de personas es el art. 45 TFUE (antiguo 39 TCE) el que establece la abolición de toda discriminación por razón de nacionalidad entre los trabajadores de los Estados miembros en el apartado segundo «con respecto al empleo, la retribución y las demás condiciones de trabajo», mientras que el apartado tercero del mismo artículo concreta el derecho «sin perjuicio de las limitaciones justificadas por razones de orden público, seguridad y salud públicas $»^{59}$.

derecho de aduana y, por tanto, constituye una restricción a la libre circulación de mercancías».

${ }^{57}$ La noción de restricción cuantitativa se ha entendido como toda disposición interna de un Estado que prohíbe o limita cuantitativamente, de forma real o de forma potencial el volumen de transacciones comerciales con otros Estados miembros, cuestión que confirmó el Tribunal de Justicia en la sentencia de 8 de febrero de 1983, Comisión c. Reino Unido, asunto C-124/81; y la de medidas de efecto equivalente, ha sido definida por el propio Tribunal en la sentencia Dassonville, entendiendo por tal «toda reglamentación comercial de los Estados miembros susceptible de obstaculizar directa o indirectamente real o potencialmente, el comercio comunitario», vid. Sentencia de 11 de julio de 1974, Dassonville, asunto C-8/74. Vid. Pérez DE LAS Heras, B., El Mercado Interior Europeo. Las libertades económicas comunitarias: mercancías, personas, servicios y capitales, op. cit., p. 42

${ }^{58} \mathrm{La}$ regulación de los arts. 28 a 37 y el 110 TFUE (antiguos arts. 23 a 31 y 90 TCE) prevén las restricciones imputables a los poderes públicos, en cuanto a las restricciones derivadas de acuerdos entre empresas o prácticas concertadas que pueden afectar al ámbito de la libertad de comercio, se regula en las normas sobre la libre competencia, en los art. 101-106 TFUE (antiguos arts. 81 a 86 TCE) pero no nos vamos a dedicar a ellos debido a que no se han planteado cuestiones en relación a conflictos con derechos fundamentales.

${ }^{59}$ Hay que considerar que el art. 45.4 TFUE establece claramente la excepción de los empleos en la administración pública, a los que no será de aplicación lo dispuesto en el art. 45. 
En cuanto a la libre prestación de servicios, los arts. 49 y 56 (antiguos arts. 43 y 49 TCE) regulan la asimilación de los nacionales de un Estado miembro a los nacionales del país de acogida para garantizar que no se produce una discriminación por razón de nacionalidad en el ámbito del derecho de establecimiento o de la prestación de servicios ${ }^{60}$.

El art. 49 TFUE prohíbe las restricciones al derecho de establecimiento; y el art. 56 TFUE prohíbe las restricciones a la libre prestación de servicios dentro de la Unión para los nacionales de los Estados miembros. Las excepciones que se posibilitan respecto a la libertad de establecimiento están basadas en razones de orden público, seguridad y salud pública, según el art. 52.1 TFUE (antiguo art. 46.1 TCE); y para la prestación de servicios se prevé que mientras se mantengan restricciones de prestación de servicios están se deben aplicar sin distinción de nacionalidad o residencia (art.61 TFUE, antiguo art. 54 TCE); y el art. 16.2 de la Directiva 2006/123/CE relativa a los servicios en el mercado interior permite las restricciones justificadas en el orden público, la seguridad pública, salud pública o protección del medio ambiente.

Es relevante, no obstante, destacar que la libre prestación de servicios es de carácter temporal frente a la libertad de establecimiento de carácter permanente en relación a su ejercicio, puesto que consiste en una instalación duradera en un Estado miembro; por otro lado, la persona que se establece en oro país queda sujeto a la legislación nacional del país de acogida, mientras que quien se desplaza a prestar un servicio continúa sometido a la ley de su Estado de origen, y la normativa del país de acogida queda para determinados supuestos previstos en la normativa de armonización, la Directiva 2006/123/CE, de 12 de diciembre, relativa a los servicios en el mercado interior posibilita condicionar esta aplicación de la legislación de acogida por razones de orden público, seguridad pública, salud pública o protec-

${ }^{60}$ Desde los comienzos de las Comunidades se pretendía conseguir la supresión progresiva de de las restricciones a estas dos libertades, para lo que se estableció un mandato a este respecto en los arts. 52 y 59 del TCEE, y se establecía que el Consejo debía antes del 31 de diciembre de 1061 adoptar dos programas generales para determinar las condiciones necesarias para la plena realización de las dos libertades, adoptándose el 18 de diciembre de 1961, pero eran documentos sin eficacia jurídica, por lo que se adoptó algunas Directivas que posibilitaron suprimir discriminaciones basadas en la nacionalidad: Directivas en materia agricultura, comercio, industria, trabajos públicos, industria cinematográfica, bancos y seguros, pero no todas las necesarias. Sin embargo, la falta de aprobación de las Directivas necesarias no impidió que el Tribunal de Justicia garantizara la eficacia jurídica directa de los entonces arts. 52 y 59 en el derecho interno, en la sentencia de 21 de junio de 1974, Reyners, asunto $\mathrm{C}-2 / 74)$. 
ción de medio ambiente siempre que se respeten los principios de no discriminación, proporcionalidad y necesidad ${ }^{61}$.

Respecto a la libre circulación de capitales, tenemos que tener en cuenta que el art. 63 TFUE (antiguo art. 56 TCE) prohíbe todas las restricciones a los movimientos de capitales y a los pagos entre Estados miembros e incluso entre éstos y terceros países ${ }^{62}$; permitiéndose solamente excepciones a los movimientos de capitales con terceros países (esto es así desde la última fase de la unión económica y monetaria iniciada el 1 de enero de 1999) prevista en el art. 63 TFUE (antiguo art. 56 TCE) y que permite a los Estados miembros mantener las restricciones que se aplicaban a 31 de diciembre de 1993 pero sólo para los movimientos especificados (inversiones directas, los movimientos de capitales relacionados con el establecimiento y la prestación de servicios financieros, y la admisión de valores en los mercados de capitales). También es importante tener en cuenta que el art. 66 TFUE (antiguo art. 59) prevé la posibilidad de que cuando en circunstancias excepcionales causen o amenacen causar dificultades graves para el funcionamiento de la Unión Económica y Monetaria, el Consejo puede decidir por mayoría cualificada a propuesta de la Comisión y previa consulta al Banco Central Europeo, medidas de salvaguardia durante un periodo máximo de seis meses y siempre que sean estrictamente necesarias, en relación con los movimientos de capitales con destino a terceros países o procedentes de ellos. Y el art. 68 TFUE (antiguo art. $58 \mathrm{TCE}$ ) que declara compatible la libre circulación de capitales con el mantenimiento por los Estados miembros de una legislación fiscal que diferencie entre contribuyentes residentes y no residentes, admitiendo una tributación más favorable para los no residentes.

\subsection{Las restricciones a las libertades económicas. El papel del tribunal de justicia en la tutela de las libertades económicas}

No se puede obviar, como hemos indicado en la introducción, el papel que ha jugado el Tribunal de Justicia en la protección de estas cuatro libertades en la construcción de la integración europea; siendo especialmente relevante para nuestro objeto de estudio la jurisprudencia que ha desarrollado las restricciones ${ }^{63}$ a las libertades econó-

${ }^{61}$ Vid. PÉREZ DE las Heras, B., El Mercado Interior Europeo. Las libertades económicas comunitarias: mercancías, personas, servicios y capitales, op. cit., p. 22.

${ }^{62}$ El Tribunal de Justicia consagró el efecto directo del art. 56 TCE en las sentencias de 14 de diciembre de 1995, Sanz de Lera y otros, asuntos acumulados C-163/94,165/94 y 250/94.

${ }^{63} \mathrm{El}$ concepto de restricciones es muy relevante, y en lo que respecta a los derechos fundamentales hay un estudio muy interesante que trata de delimitar precisa- 
micas fundamentales previstas en los Tratados a partir de la libre circulación de mercancías, es la jurisprudencia que la ha tratado la que ha adquirido una mayor relevancia, desarrollo y que ha terminado influyendo en el ámbito de las otras libertades.

Así, y respecto a la libre circulación de mercancías, para cuya garantía, como hemos visto, se prohibían las restricciones o medidas de efecto equivalente, el Tribunal de Justicia precisó el concepto de estas medidas de efecto equivalente en la sentencia Dassonville ${ }^{64}$; pero después permitió restricciones que persiguieran intereses legítimos no contemplados de forma expresa en los Tratados en la sentencia Cassis de Dijon $^{65}$.

Efectivamente, en la sentencia Dassonville se construye la base de la doctrina sobre la "medida de efecto equivalente», entendiendo por tal «toda reglamentación comercial de los Estados miembros susceptible de obstaculizar, directa o indirectamente, real o potencialmente, el comercio intracomunitario» lo que sirve para clarificar tanto la noción de medidas de efecto equivalente como la de restricciones justificadas ${ }^{66}$. En definitiva, toda regulación estatal que pueda suponer un obstáculo directo o indirecto, real o potencial al comercio intracomunitario se considera como una «medida de efecto equivalente», sin necesidad que exista una discriminación directa o indirecta de productos de otros Estados miembros; concepto que se ha mantenido en la jurisprudencia del Tribunal de Justicia ${ }^{67}$.

Se trataría de que concurrieran dos elementos, que se trate de una medida estatal, y que ésta produzca un efecto restrictivo sobre los intercambios intracomunitarios ${ }^{68}$. Pero dicha medida estatal puede ser fruto de todos los órganos del Estado, ya sean centrales, federales,

mente el concepto de restricciones a los derechos fundamentales, véase CABEzUDo BAJO, M. J., "La restricción de los derechos fundamentales: un concepto en evaolución y su fundamento constitucional», Revista de Derecho Político, n. ${ }^{\circ}$ 77, 2010, pp. 143-182.

${ }^{64}$ Dassonville, C-8/74, op. cit.

${ }^{65}$ Sentencia de 20 de febrero de 1979, Rewe-Zentral AG c. Bundesmonopolverwaltung für Branntwein, asunto C-120/78.

${ }^{66}$ WyATT, D., "Article 30 and Non-Discriminatory Trade restrictions», European Law Review, n. ${ }^{\circ}$ 6, 1981, p. 185.

${ }^{67}$ Como dice Chalmers, «These words have been repeated as an item of faith by the Court and comentators even since» Vid. CHALMERs, D., "Free movement of goods within the European Community: an unhealthy addiction to scotch whisky», International and Comparative Law Quarterly, v. 42, n. ${ }^{\circ}$ 2, p. 275.

${ }^{68}$ Page, A. C., «The Concept of Measures Having an Effect Equivalent to Quantitative Restrictions», European Law Review, n. ${ }^{\circ}$ 2, 1977, p. 102. 
regionales, municipales, o bien correspondan a los poderes legislativo, ejecutivo o judicial ${ }^{69}$.

La doctrina Dassonville suponía que el TJCE podía controlar cualquier norma nacional que potencialmente pudiera afectar al mercado, incluso en ámbitos de competencia estatal ${ }^{70}$. Además, produciría un efecto «spillover», esto es, «de extensión y potenciación de sus efectos a ámbitos diferentes a los que estaba originalmente prevista ${ }^{71}$; pudiendo llegar a afectar considerablemente a las regulaciones nacionales ${ }^{72}$.

Sin duda alguna, Dassonville es importante, porque relanza la libre circulación de mercancías y sirve en su momento para intensificar el proceso de integración a través del mercado ${ }^{73}$; si bien no se puede obviar que también ha evolucionado pues en la sentencia Keck y Mithoouard flexibiliza su examen aceptando restricciones que tengan efecto en todos los operadores comunitarios ${ }^{74}$.

${ }^{69}$ Estamos ante una definición amplia y extensa de las medidas de efecto equivalente, lo que ha supuesto que se incluyan como tales reglamentaciones comerciales de los Estados miembros sin efectos proteccionistas, pero que suponían obstáculos de forma indirecta al comercio intracomunitario.

${ }^{70}$ Poiares Maduro, L. M., «Striking the Elusive Balance Between Economic Freedom and Social Rights in the European Union», op. cit., p 451; RoDRIGUEZ-PIÑERO Royo, M., «Libertades económicas y derechos sociales en la Unión Europea», XX Congreso Nacional Asociación Española de Derecho del Trabajo y de la Seguridad Social, Logroño, mayo de 2009, www.aedtss.com/TERCERA_PONENCIA_MRPR.doc, pp. 12 y ss.

${ }^{71}$ Rodriguez-PiÑero Royo, M., «Libertades económicas y derechos sociales en la Unión Europea», op. cit., p. 12.

${ }^{72}$ Estos peligros fueron pronto puestos de manifiesto por DAVIES, en la medida que entendía que las reglas desarrolladas por el Tribunal de Justicia «son potencialmente muy destructivas de las regulaciones nacionales», DAVIES, P., «Market integration and social policy in the Court of Justice», Industrial Law Journal, n. ${ }^{\circ}$ 24, 1995, p. 587.

${ }^{73}$ Algunos autores han estudiado el fenómeno de la potenciación de la interacción por medio del mercado desde una visión funcionalista explicando incluso la evolución desde el mercado común, el mercado interior, y la unión económica y monetaria. Vid. de nuevo RodRIGUEz-PIÑERo RoYo, M., "Libertades económicas y derechos sociales en la Unión Europea», op. cit., p. 13.

Debemos señalar que Dassonville también motivó que la Comisión emitiera un comunicado relativo a las consecuencias de la sentencia (Communication from the Commission concerning the consequences of the judgment given by the Cour of Justice on 20 february 1979 in Case 120/78 («Cassis de Dijon») [1980] OJ C/256/2).

${ }^{74}$ Efectivamente, con la sentencia de 24 de noviembre de 1993, Keck y Mithhouard, asuntos C-267 y 268/91, el Tribunal de Justicia refine su jurisprudencia Dassonville considerando que «la aplicación a productos de otros Estados miembros de disposiciones nacionales que limiten o prohíban ciertas modalidades de venta no es susceptible de obstaculizar directa o indirectamente, real o potencialmente, el comercio entre los Estados miembros en el sentido de la jurisprudencia Dassonville, siempre que dichas disposiciones se apliquen a todos los operadores afectados que ejerzan su actividad en el territorio nacional y siempre que afecten del mismo modo, de he- 
Pero hay que tener en cuenta no sólo la famosa fórmula Dassonville, de que todas las medias nacionales que puedan afectar directa o indirectamente, de forma actual o potencial a una libertad intracomunitaria deben ser consideradas como medidas de efecto equivalente, sino que el complemento a la misma es la consideración de que los Estados miembros pueden legítimamente tomar medidas que persiguieran un interés público, esto es, la doctrina Cassis de Dijon ${ }^{75}$.

En esta sentencia introduce dos cuestiones fundamentales: En primer lugar el principio de reconocimiento mutuo; y en segundo lugar, la doctrina de las exigencias imperativas o mandatory requirements.

Este caso se suscitó en relación a una normativa alemana que imponía para la comercialización de ciertos licores un contenido alcohólico de 25 grados mínimo, tanto de origen alemán como extranjero. Un comerciante alemán no pudo importar crema del famoso licor francés crema de Cassis, puesto que su contenido era inferior a 20 grados. La justificación que esgrimieron las autoridades alemanas era la necesidad de informar al consumidor alemán sobre las consecuencias que podía tener para su salid bebidas con un grado de alcohol inferior al exigido en la legislación

El Tribunal de Justicia entendió que tal objetivo de información podía lograrse con medidas que fueran menos restrictivas como la introducción de una advertencia en la etiqueta del producto, por lo que no justificaba una medida como la impuesta que constituía una medida de efecto equivalente a una restricción cuantitativa, ya que producía el efecto de excluir del mercado alemán licores fabricados y comercializados legalmente en otros Estados miembros protegiendo los productos alemanes.

Por tanto, introduce el principio de reconocimiento mutuo, por el que los Estados miembros deben aceptar la entrada, venta y consumo en su territorio de productos que están legalmente fabricados y comercializados en otros Estados miembros; y por otro lado la doctrina de las exigencias imperativas de interés general que podrían justificar como los motivos establecidos de forma expresa en el art. 30 TCE

cho y de derecho, a la comercialización de los productos nacionales y a la de los procedentes de otros Estados miembros» (Apartado 16 de la sentencia) En definitiva, flexibiliza su examen aceptando restricciones que tengan efecto en todos los operadores comunitarios.

${ }^{75}$ Biondi, A., «Free Trade, a Mountain Road and the Right to Protest: European Economic Freedoms and Fundamental Individual Rights», European Human Rights Law Review, v. 9, n. ${ }^{\circ}$ 1, 2004, p. 54. 
(ahora el artículo 26 TFUE) restricciones a la libre circulación de mercancías ${ }^{76}$.

En concreto el Tribunal calificaba como exigencias imperativas los supuestos de «la efectividad de los conflictos fiscales», «la lealtad de las transacciones comerciales», «la protección de la salud pública», y «la defensa de los consumidores».

La razón de esta doctrina es sencilla, las listas de restricciones previstas en los Tratados, como hemos visto, son limitadas, y además se elaboraron en un momento histórico concreto; y esto motivó el desarrollo jurisprudencial de otras exigencias de interés general que pueden justificar las restricciones, por lo que los supuestos reconocidos en Cassis no constituían una lista exhaustiva.

En cualquier caso, nos interesa la cuestión de las exigencias imperativas y el desarrollo de la jurisprudencia Cassis de Dijon, ya que por esta vía se ha permitido que los Estados miembros establezcan restricciones a la libre circulación de mercancías por diversos motivos. Pero lo más relevante de todo es que si bien nacida en el ámbito de la libre circulación de mercancías, esta doctrina de las exigencias imperativas se ha aplicado a las otras libertades del mercado ${ }^{77}$ : a la libre prestación de servicios, en la sentencia Manfred Säger ${ }^{78}$; a la libre circulación de trabajadores, en la sentencia Bosman ${ }^{79}$; a la libertad de

${ }^{76} \mathrm{Y}$ por tanto estas restricciones justificarían una ruptura del principio de reconocimiento mutuo, si bien condiciona la posibilidad de justificación de las restricciones a que tales restricciones u obstáculos sean medidas indistintamente aplicables, tanto a productos nacionales como importados. Los obstáculos a la libre circulación resultantes de las disparidades de las legislaciones nacionales sobre fabricación y comercialización de productos serán aceptadas en la medida en que sean necesarias para proteger intereses u objetivos generales que no satisfaga la legislación de origen del producto.

${ }^{77}$ Aunque quizá también se pueda extender al Derecho procesal, como demostrarían, en opinión de Rossi y CuRzon, las sentencias Schijndel (Sentencia de 15 de junio de 1995, Jeroen van Schijndel, asunto C-430/93) y Peterbroeck (Sentencia de 14 de diciembre de 1995, Peterbroeck, asunto C-312/93). Vid. Rossi, L. S., y CuRson, S. J., "What «Rule of Reason» for the EU Internal Market?», Studi sulla inegrazione europea, 2008, n. ${ }^{\circ}$ 2, p. 301.

${ }^{78}$ Sentencia de 25 de julio de 1991, Manfred Säger, asunto C-76/90.

${ }^{79}$ Sentencia de 15 de diciembre de 1995, Jean Marc Bosman, asunto C-415/93.

Para un estudio actual de la sentencia Bosman, vid. BogaERT, S. van den., "Bosman: The Genesis of European Sports Law», en Poiares Maduro, M., y Azoulai, L. (eds.), The Past and Future of EU Law: The Classics of EU Law Revisited on the 50th Anniversary of the Rome Treaty, op. cit., pp. 488-497; Infantino, G., y Mavroidis, P. C., "Inherit the Wind: A Comment on the Bosman Jurisprudence», en PoIARES MADURO, M., y AzoulaI, L. (eds.), vid supra, pp. 498-504. 
establecimiento, en la sentencia Gebhard ${ }^{80}$; y a la libre circulación de capitales en la sentencia Comisión c. Bélgica ${ }^{81}$.

Entre las exigencias imperativas que han justificado restricciones se pueden destacar, entre otros intereses ${ }^{82}$ : la protección de la salud ${ }^{83}$, la protección de los consumidores ${ }^{84}$; el medio ambiente ${ }^{85}$, la cultura ${ }^{86}$, la pluralidad de medios ${ }^{87}$; los objetivos sociales $^{88}$; la lucha contra la inflación ${ }^{89}$; el patrimonio artístico, histórico o cultural ${ }^{90}$; la protección

${ }^{80}$ Sentencia de 31 de noviembre de 1995, Reinhard Gebhard, asunto C-55/94.

${ }^{81}$ Sentencia de 4 de junio de 1992, Comisión c. Reino de Bélgica, asunto C-503/99.

${ }^{82}$ No podemos deternos a realizar un estudio pormenorizado de cada uno de estos intereses, pero tratamos de citar los más relevantes así como las sentencias que se refieren a los mismos.

${ }^{83}$ Sentencias de 1 de febrero de 2001, Criminal proceedings against Dennis Mac Quen, Derek Pouton, Carla Godts, Youssef Antoun adn Grandvision Belgium SA, asunto C-108/96; de 8 de marzo de 2001, Konsumentombudsmannen (KO) et Gourmet International Products AB (GIP), asunto C-405/98; de 11 de julio de 2002, Deutsche Paracelsus Schulen fur Naturheilverfahren GmbH c. Kurt Grabner, asunto C-294/00; de 3 de julio de 2003, Joseph Lennox c. Industria Lavorazione Carni Ovine, asunto C-220/01; de 11 de diciembre de 2003, Deutscher Apothekerverband eV c. 0800 DocMorris NV and Jacques Waterval, asunto C-322/01; de 2 de diciembre de 2004, Commission of the European Communities c. Netherlands, asunto C-41/02; de 14 de diciembre de 2004, $R$ (on the application of Swedish Match AB) c. Secretary of Statte for Health, asunto C-210/03; de 10 de noviembre de 2005, Comisión c. República Portuguesa, asunto C-432/03; de 5 de junio de 2007, Klasd Rosengre y otros c. Riksaklagarem, asunto C-170/04.

${ }^{84}$ Aquí encontramos las Sentencias Deutscher Apothekerveband, op. cit., vid supra; y Klasd Rosengren y otros, op. cit., vid. supra.

${ }^{85}$ Sentencias de 20 de septiembre de 1988, Commission c. Denmark, asunto C-3027/86; de 21 de noviembre de 2001, François de Coster c. Collage des bourgmestre et échevins de Watermael-Boitsfort, asunto C-17/00; de 13 de marzo de 2001, PreussenElektra AG et Schleswag AG, asunto C-379/98; de 17 de septiembre de 2002, Concordia Bus Finland $O y$ Ab, antes Stagecoach Finland Oy Ab c. Helsingin kaupunki and HKL-Bussiliikenne, asunto C-513/99; de 15 de noviembre de 2005, Comisión c. República Federal de Alemania, asunto C-320/03; 21 de febrero de 2008, Comisión c. República Francesa, asunto C-201/06.

${ }^{86}$ Sentencia de 26 de febrero de 1991, Comisión c. República de Francia, asunto C-154/89.

${ }^{87}$ Sentencia de 26 de junio de 1996, Vereinigte Familiapress Zeitungsverlags - und Vertriebs GmbH c. Bauer Verlag, asunto C-368/9.

${ }^{88}$ Sentencias de 23 de noviembre de 1999, Arlade c. Leloup, asunto C-369/96 (mejora de las condiciones de trabajo); de 27 de octubre de 1992, Hanns Martin Bachmann c. Estado Belga, asunto C-204/90 (protección de la coherencia del sistema tributario); de 21 de septiembre de 1999, Albany International BV c. Stiching Bedrijfspensionefonds Textielindusrie, asunto C-67/96 ( respecto al alto nivel de empleo y protección social y referida a la libre competencia).

${ }^{89}$ Sentencia de 29 de noviembre de 1983, Roussel, asunto C-181/82.

${ }^{90}$ Sentencias de 23 de octubre de 2003, RTL Television GmbH c. Niedersachsische Landesmedienanstald fur privaten Rundfunk, asunto C-245/01; de 5 de octubre de 1994, TV10 c. Commissariaat voor Media, C-23/93; de 3 de febrero de 1993, Verónica Omroep organisatiem, asunto C-148/91; de 25 de julio de 1991, Stichting Collectieve Antennevoorziening Gorda y otros c. Commissariaat voor de Media, asunto C-288/89; 
de los trabajadores ${ }^{91}$; la lucha contra el turismo de la droga y las molestias que acarrea ${ }^{92}$; e incluso quizá también los derechos fundamentales ${ }^{93}$.

Ahora bien, respecto a los derechos fundamentales se debe realizar una mención aparte, pues hay que considerar la posibilidad de que la posición mantenida por el Tribunal de Justicia no sea el de la jurisprudencia tradicional sobre las restricciones a las libertades económicas, sino una nueva posición en la que los derechos fundamentales juegan al mismo nivel que las libertades económicas ${ }^{94}$.

de 25 de julio de 1991, Comisión c. Reino de los Países Bajos, asunto C-353/89; de 26 de febrero de 1991, Comisión c. Italia, asunto C-180/89; de 26 de abril de 1988, Bond van Adverteeders, asunto C-352/85.

${ }^{91}$ Sentencias de 23 de noviembre de 1999, Arblade, asuntos acumulados C-369 y 376/96; de 25 de octubre de 2001, Finalarte, asuntos acumulados C-49, 50, 52 y 54/98; y de 21 de octubre de 2004, Comisión c. Luxemburgo, asunto C-445/03, entre otras.

${ }^{92}$ Sentencia de 16 de diciembre de 2010, Marc Michel Josemans c. Burgemeester van Maastrich, asunto C-137/09.

${ }_{93}$ Sentencias de 12 de junio de 2003, Eugen Schmidberger, Inernationale Transporte und Planzüge, asunto C-112/00; y de 14 de octubre de 2004, Omega, asunto C-36/02.

${ }^{94}$ Efectivamente, parte de la doctrina ha considerado que las sentencias Schmidberger y Omega supondrían la aplicación de la doctrina de los mandatory requeriments a los derechos fundamentales, vid. Heliskoski, J., «Fundamental Rights versus Economic Freedoms in the European Union: Which paradigm?», op. cit., p. 339; Díaz Crego, M., Protección de los derechos fundamentales en la Unión Europea y en los Estados miembros, Reus, Madrid, 2009, pp. 152-153; KRZEMINSKA, J., «Free speech Meets Free Movement - How fundamental really is "Fundamental"? The Impact of Fundamental Rights on Internal Market Law», ZERP-Diskussionspapier 3/2005, http://ssrn.com/abstract=1134809, pp. 7 y ss; y LIDFELDT, M., Fundamental Rights in European Union - Towards Higher Law of the Land?, op. cit., p. 215; RoMÁn GonZÁLEZ, E., «Libertades económicas y derechos fundamentales. La doctrina de los Mandatory Requirements en la Jurisprudencia del TJCE», Boletín Mexicano de Derecho Comparado, nueva serie, n. ${ }^{\circ} 127,2010$, pp. 538 y ss.

En nuestra opinión en realidad podemos apreciar una ponderación entre libertades económicas y derechos fundamentales como valores fundamentales del Derecho de la Unión Europea. En este sentido vid. SARrión Esteve, J., «Los conflictos entre libertades económicas y derechos fundamentales en la jurisprudencia del Tribunal de Justicia de la Unión Europea», Revista de Derecho Político, n. ${ }^{\circ}$ 81, 2011, pp. 279-412.

Sentencia de 10 de noviembre de 1982, Walter Rau Lebensmittelwerke c. De Smedt $P V B$, asunto C-261/81. En esta sentencia el TJCE deja claro que es necesario que los mandatory requirements sean proporcionales al objetivo que persiguen, y si hay varias opciones para conseguir los mismos objetivos se debe escoger el menos restrictivo para la libre circulación de mercancías. El Tribunal de Justicia utilizaría así un test de dos escalones. Así lo razona LindLFELT «A two-step test, i.e. the test of suitability (means and ends) and the test of necessity (weighing of interests) in order to determine proporitionality». Vid. LindfeldT, M., Fundamental Rights in Eruopean UnionTowards Higher Law of the Land?, op. cit., p. 207.

Sobre esta exigencia de proporcionalidad se pueden ver las Sentencias de 7 de marzo de 1990, GB-INNO-BM c. Confederation du commerce luxembourgeois, asunto C-362/88; de 4 de junio de 1992, Debus, asuntos C-13/91, y C-113/91, apartado 16; de 5 de mayo de 1998, Reino Unido c. Comisión, asunto C-180/1996, apartados 50-53; de 
En cualquier caso, las medidas restrictivas deben ajustarse a lo previsto en los Tratados y también en la propia jurisprudencia del Tribunal de Justicia.

Esta jurisprudencia exige que la medida nacional debe ser proporcionada, esto es, apropiada y necesaria para el objetivo que la justifica, y la menos restrictiva entre las que fueran apropiadas, no pudiendo causar inconvenientes desmesurados en relación con el fin perseguido por la medida, desde la temprana sentencia Rau Lebensmittelwerke $e^{95}$.

Así, en casi todos estos supuestos el TJCE ha optado por realizar un examen de la proporcionalidad exhaustivo, concediendo poco margen al juez nacional. Pero no siempre el examen de proporcionalidad es idéntico. Como ejemplo de la aplicación de un test de proporcionalidad más riguroso o estricto, tenemos la sentencia Comisión c. Dinamarca $^{96}$, donde el TJCE entiende que la medida nacional no es proporcional cuando sus efectos negativos son excesivos comprados con el valor intrínseco de la medida misma. Aplica una mayor flexibilización para determinados supuestos como la protección del consumidor en la jurisprudencia sobre los juegos de azar ${ }^{97}$. Y cuando la restricción se justifica en la protección del pluralismo de prensa, encontramos una evolución puesto que en un primer momento el Tribunal no fue flexible respecto a la legislación holandesa de los sectores

3 de julio de 2003, Joseph Lennox, op. cit., apartados 76 y ss.; de 5 de junio de 2007, Klasd Rosengren y otros, op. cit., apartados 43-57.

${ }^{95}$ Sentencia de 10 de noviembre de 1982, Walter Rau Lebensmittelwerke c. De Smedt PVB, asunto C-261/81. En esta sentencia el TJCE deja claro que es necesario que los mandatory requirements sean proporcionales al objetivo que persiguen, y si hay varias opciones para conseguir los mismos objetivos se debe escoger el menos restrictivo para la libre circulación de mercancías. El Tribunal de Justicia utilizaría así un test de dos escalones. Así lo razona LiNDLFELT "A two-step test, i.e. the test of suitability (means and ends) and the test of necessity (weighing of interests) in order to determine proporitionality». Vid. LINDFELDT, M., Fundamental Rights in Eruopean Union - Towards Higher Law of the Land?, op. cit., p. 207.

Sobre esta exigencia de proporcionalidad se pueden ver las Sentencias de 7 de marzo de 1990, GB-INNO-BM c. Confederation du commerce luxembourgeois, asunto C-362/88; de 4 de junio de 1992, Debus, asuntos C-13/91, y C-113/91, apartado 16; de 5 de mayo de 1998, Reino Unido c. Comisión, asunto C-180/1996, apartados 50-53; de 3 de julio de 2003, Joseph Lennox, op. cit., apartados 76 y ss.; de 5 de junio de 2007, Klasd Rosengren y otros, op. cit., apartados 43-57.

${ }^{96}$ Sentencia de 20 de septiembre de 1980, Comisión c. Dinamarca, asunto C-302/86.

${ }^{97}$ Hay que tener en cuenta que esta jurisprudencia comienza con la Sentencia de 24 de marzo de 1994, Her Majesty's Customs and Excise c. Gerhart Schindler y Joerg Schindler, asunto C-275/92, donde ya otorgaba un amplio margen nacional. 
de prensa, radio y televisión ${ }^{98}$; mientras que en cambio sí lo hace posteriormente en la sentencia Familiapress, con la regulación austríaca ${ }^{99}$.

Aunque, sin lugar a dudas, el supuesto de aplicación más flexible del test o examen de proporcionalidad, dejando un mayor margen a las autoridades nacionales, lo encontramos en la sentencia Omega, donde precisamente se resuelve un supuesto de conflicto con un derecho fundamental de la Constitución alemana, la dignidad humana, frente a la libre prestación de servicios ${ }^{100}$

El desarrollo de esta jurisprudencia sobre las exigencias imperativas puede ser el reflejo de la necesidad de ponderar las reglas generales relativas a las libertades económicas fundamentales y sus excepciones, y por tanto, el Tribunal de Justicia lo que haría sería resolver de forma ponderada y racional el conflicto entre los diferentes intereses en juego, aplicando de forma analógica la rule of reason americana ${ }^{101}$; y en los casos donde en el conflicto intervienen frente a las li-

${ }^{98}$ Sentencias de 25 de junio de 1991, Stichting Collective Antennevoorziening Gorda y otros c. Commissariaat voor de Media, asunto C-288/89; y de 25 de julio de 1991, Comisión c. Reino de los Países Bajos, asunto C-353/89. Y la línea jurisprudencial ha continuado. Vid. las Sentencias de 11 de septiembre de 2003, Associaçao Nacional de Operadores de Máquinas Recretativas (Anomar) y otros c. Estado portugués, asunto C-6/01, sobre la normativa nacional que limitaba el derecho de explotación de juegos de azar a las salas de casinos; de 21 de octubre de 1999, Questore di verona c. Diego Zenatti, asunto C-67/98, en relación con la normativa nacional que prohibía la recogida de apuestas y reserva a ciertos organismos el derecho a organizar las que están autorizadas; de 21 de septiembre de 1999, Markku Juhani Läärä, Costswold Microsystem Ltd y Oy Transatlantic Software Ltd c. Jyväskylä y Estado Finandés, asunto C-124/1997, respecto a una normativa nacional que reserva a un organismo público la explotación de las máquinas tragaperras. Diferente parece ser el caso de la sentencia de 6 de marzo de 2007, Massimiliano Placanica y otros, asuntos acumulados C-338, 359 y 360/04; y también la sentencia de 6 de noviembre de 2003, Piergiorgio Gambelli y otros, asunto C-243/01, respecto a normativa nacional que sancionaba penalmente el ejercicio de actividades de recogida, aceptación, registro transmisión de apuestas deportivas cuando no hay concesión o autorización del Estado, puesto que en este caso no parecía perseguir la protección de los consumidores.

${ }^{99}$ Sentencia de 26 de junio de 1996, Vereinigte Familiapress Zeitungsverlags - und Vertriebs GmbH c. Bauer Verlag, C-368/95.

${ }^{100}$ Sentencia Omega, op. cit. No podemos obviar que esto a la postre plantea el problema del diálogo entre Tribunales, sobre esta cuestión un trabajo muy actualizado del problema y el diálogo entre jurisdicciones europea y nacionales es el de TENORIO SÁNCHEZ, P. J., «Diálogo entre tribunales y protección de los derechos fundamentales en el ámbito europeo", Revista General de Derecho Europeo, n. . 31, 2013.

${ }^{101}$ Se ha entendido que desde Cassis de Dijon, el Tribunal de Justicia habría introducido la técnica de la rule of reason propia del Derecho anglosajón, conforme a la que un principo general puede ser modulado de forma racional en cada caso concreto. Sobre la introducción de esta rule of reason por parte del TJCE vid. Rossi, L., y Curzon, S. J., "What «Rule of Reason» for the EU Internal Market?», op. cit., 
bertades fundamentales derechos fundamentales, la ponderación se hace más necesaria que nunca, ya que ambos ostentarían el mismo estatus «fundamental» ${ }^{102}$.

\section{CONCLUSIONES}

Como hemos visto el Tribunal de Justicia ha tenido un papel relevante en la tutela de las libertades económicas, y en particular de la libre circulación de mercancías, desarrollando toda una jurisprudencia que sobre la base del principio de proporcionalidad ha tratado de ponderar en todo momento los valores e intereses en conflicto a efectos de poder dar la respuesta mejor más adecuada que garantice la doble dimensión de la integración europea, esto es, la económica y la social, pero donde las libertades económicas, en cuanto valores fundamentales de la integración europea constituyen el punto de partida de la jurisprudencia, y por tanto, son protegidas a priori, debiendo estar justificadas y ser proporcionadas las restricciones adoptadas sobre las mismas.

En este sentido, y vista la regulación jurídica de los Tratados y el espacio preponderante que tenían las libertades económicas, es importante tener en consideración las exigencias imperativas que han justificado restricciones a las libertades económicas para tutelar, entre otros intereses: la protección de la salud, la protección de los consumidores; el medio ambiente, la cultura, la pluralidad de medios; los objetivos sociales; la lucha contra la inflación; el patrimonio artístico, histórico o cultural; la protección de los trabajadores; la lucha contra el turismo de la droga y las molestias que acarrea.

Además, la jurisprudencia ha nacido y se ha desarrollado a partir de la libre circulación de mercancías (Cassis, Dassonville) extendiéndose posteriormente a las otras libertades económicas.

En cualquier caso, el desarrollo de la jurisprudencia sobre las exigencias imperativas puede ser el reflejo de la necesidad de ponderar las reglas generales relativas a las libertades económicas fundamentales y sus excepciones, y por tanto, el Tribunal de Justicia lo que haría sería resolver de forma ponderada y racional el conflicto entre los di-

pp. 299-301 y 301; Rodríguez Iglesias, G. C., y Liñán Nogueras, D. J., (dir.), El Derecho Comunitario Europeo y su aplicación judicial, Civitas, Madrid, 1993, p. 750.

${ }^{102}$ Vid. SARRIÓN Esteve, J., ««Los conflictos entre libertades económicas y derechos fundamentales en la jurisprudencia del Tribunal de Justicia de la Unión Europea», op. cit. 
ferentes intereses en juego, aplicando de forma analógica la rule of reason americana.

Además, en los casos donde en el conflicto intervienen frente a las libertades fundamentales derechos fundamentales, la ponderación se hace más necesaria que nunca, pues ambos gozarían del estatus de «fundamental», por ello la posición mantenida por el Tribunal en Omega, Viking, Laval, etc. mostraría se alejaría de la jurisprudencia tradicional sobre las restricciones a las libertades económicas, a otra en la que los derechos fundamentales juegan al mismo nivel que las libertades económicas.

Conforme el Tribunal de Justicia avance en esta jurisprudencia, veremos que puede asumir un rol de auténtico Tribunal constitucional en el ámbito del Derecho de la Unión Europea, y en dicha jurisprudencia las libertades económicas, y en particular la libre circulación de mercancías están llamadas a ocupar una posición prevalente para garantizar la dimensión económica de la integración europea.

\section{BIBLIOGRAFÍA}

ALDECOA LUZARRAGA, F., La integración europea. Análisis históricoinstitucional con textos y documentos [II Génesis y desarrollo de la Unión Europea (1979-2002), Tecnos, Madrid, 2002.

ALONSO GARCÍA, R., Sistema Jurídico de la Unión Europea, 2. ${ }^{\text {a }}$ edición, Thomsom-Civitas, Madrid, 2010, pp. 15-56.

BAQUERO CRUZ, J., Entre competencia y libre circulación. El Derecho constitucional económico de la Comunidad Europea, Civitas, Madrid, 2002.

BARNARD, C., y SCOTT, J. (eds), The Law of the Single European Market, Hart Publishing, 2002.

BARNARD, C., The substantive law of the EU, The four freedoms, Oxford University Press, Oxford, 2007

BENLLOCH DOMENECH, C. (dir.), Construyendo ciudadanía a través de las TICs, Comares, 2010.

BIONDI, A., «Free Trade, a Mountain Road and the Right to Protest: European Economic Freedoms and Fundamental Individual Rights», European Human Rights Law Review, v. 9, n. ${ }^{\circ}$ 1, 2004, pp. 51-61. 
BOGAERT, S. van den., "Bosman: The Genesis of European Sports Law», en POIARES MADURO, M., y AZOULAI, L. (eds.), The Past and Future of EU Law: The Classics of EU Law Revisited on the 50 $0^{\text {th }}$ Anniversary of the Rome Treaty, Hart Publishing, Oxford y Portland, 2010, pp. 488-497.

BORRAJO INIESTA, I., «Los Tribunales constitucionales ante el Derecho comunitario. Intervención de Ignacio Borrajo Iniesta», en en MARTÍNEZ DE VELASCO, H. H., y ZAMORA ZARAGOZA, F. J. (dir.), La articulación entre el derecho comunitario y los derechos nacionales: algunas zonas de fricción, Estudios de derecho Judicial, n. ${ }^{\circ}$ 95, CGPJ-Centro de Documentación Judicial, Madrid, 2006, pp. 237-257.

CABEZUDO BAJO, M. J., «La restricción de los derechos fundamentales: un concepto en evaolución y su fundamento constitucional», Revista de Derecho Político, n. ${ }^{\circ}$ 77, 2010, pp. 143-182.

CALONGE VELÁZQUEZ, A., «Preparación y elaboración de la Constitución para Europa: la Convención sobre el futuro de Europa», Revista de Derecho de la Unión Europea, n. ${ }^{\circ}$ 8, 2005, pp. 53-70.

CALVANO, R., La Corte di giustizia e la costituzione europea, Cedam, Padova, 2004.

CAPELLETI, M., SECCOMBE, M., y WEILER, J. (eds.), Integration though law. Europe and the American Federal Experience, De Gruyter, Berlín y Nueva York, 1985.

CASSESE, S., «La costituzione economica europea», Revista Italiana di Diritto Pubblico comunitario, n. ${ }^{\circ}$ 6, 2008, pp.907-922.

CASTILLO DAUDÍ, M., "Los derechos humanos en la Unión Europea», Cuadernos de Integración Europea, n. ${ }^{\circ}$ 4, 2006.

- «La protección internacional de los Derechos Humanos en el plano regional (II): La obra de las Comunidades Europeas y de la Unión Europea», en BOU FRANCH, V., y CASTILLO DAUDÍ, M., Curso de Derecho Internacional de los Derechos Humanos, 2. ${ }^{a}$ edición, Tirant lo Blanch, Valencia, 2010, pp. 157-176.

CASTRO OLIVEIRA, A., "Workers and other persons: step-by-step from movement to citizenship", Common Market Law Review, v. 39, n. ${ }^{\circ} 1,2002$, pp. 77-127.

CHALMERS, D., «Free movement of goods within the European Community: an unhealthy addiction to scotch whisky", International and Comparative Law Quarterly, v. 42, n. ${ }^{\circ}$ 2, 1993, pp. 269-294. 
CONSTANTINESCO, V., "La constitution économique de la CEE», Revue Trimestrielle de droit européen, n. ${ }^{\circ} 2,1977$, pp. 244-281.

CRAIG, P. y DE BURCA, G. (dir.), The Evolution of EU Law, Oxford Universtity Press, Oxford, 2008.

DAVIES, G., European Union Internal market Law, Cavendish Publishing, Londres, 2002.

DAVIES, P., «Market integration and social policy in the Court of Justice», Industrial Law Journal, n. ${ }^{\circ} 24,1995$, pp. 49-77.

DEDMAN, M. J., The origins and Development of the European Union (1945-2008). A History of European Integration, Routledge, 2. a edición, Routledge, Abingdon, Oxon, 2010.

DEHOUSSE, R., y WEILER, J., «The Dynamics of European integration: the legal dimension», en WALLACE, W. (ed.), The Dynamics of European Integration, Pinter, Londres, pp. 242-260.

DÍAZ CREGO, M., Protección de los derechos fundamentales en la Unión Europea y en los Estados miembros, Reus, Madrid, 2009.

DÍEZ PICAZO, L. M., La naturaleza de la Unión Europea, Civitas, 2009.

GILLINGHAM, J., European Integration, Cambridge University Press, Cambridge, 2003.

JOERGES, C., «Taking the Law Seriously: On Political Science and the Role of Law in the Process of European Integration», European Law Journal, n. ${ }^{\circ} 2$, 1996, pp. 105-135.

GÓMEZ SÁNCHEZ, Y., La Unión Europea en sus documentos, Centro de Estudios Políticos y Constitucionales, Madrid, 2000.

GONZÁLEZ VAQUÉ, L., «El nuevo mecanismo de intervención para asegurar la libre circulación de mercancías en situaciones conflictivas», Gaceta Jurídica de la CE, B-128, 1997, pp. 17-24.

GORMLEY, L. W., EU Law of Free Movement of Goods and Customs Union, Oxford University Press, Oxford, 2008.

GUTIÉRREZ ESPADA, C., El sistema institucional de las Comunidades Europeas: de los tratados constitutivos y el Acta Única al proyecto de Tratado sobre la Unión Europea, Tecnos, Madrid, 1988.

HELISKOSKI, J., «Fundamental Rights versus Economic Freedoms in the European Union: Which paradigm?», en PETMAN, J., KLABBERS, H. (eds.), Nordic Cosmopolitanism: Essays in Internatio- 
nal Law for Martti Koskenniemi, Martinus Nijhoff Publishing, Leiden, 2004, pp. 417-443.

HINOJOSA, L. M., La regulación de los movimientos internacionales de capital desde una perspectiva de europea, Mc Graw Hill, Madrid, 1999.

INFANTINO, G., y MAVROIDIS, P. C., «Inherit the Wind: A Comment on the Bosman Jurisprudence», en POIARES MADURO, M., y AZOULAI, L. (eds.), The past and Future of EU Law: The Classics of EU Law Revisited on the 50th Anniversary of the Rome Treaty, Hart Publishing, Oxford y Portland, 2010, pp. 498-504.

JACOBS, F. G, «The evolution of the European Legal Order», Common Market Law Review, v. 41, n. ${ }^{\circ} 2$, 2004, pp. 303-316.

KELLER, H., y SCHNELL, C., "International Human Rights Standards in the EU - A Tightrope Walk between Reception and Parochialism?», Swiss Review of International and European Law, n. ${ }^{\circ}$, 2010, pp. 3-37.

KRZEMINSKA, J., «Free speech Meets Free Movement - How fundamental really is 'Fundamental'? The Impact of Fundamental Rights on Internal Market Law», ZERP-Diskussionspapier 3/2005, http://ssrn.com/abstract=1134809.

LINDFELT, M., Fundamental Rights in the European Union - Towards Higher Law of the Land? A Study of the Status of Fundamental Rights in a Broader Constitutional Setting, Åbo Akademi University, Åbo, 2007.

LO FARO, A., «Diritti sociali e libertà economiche del mercato interno: considerazioni minime in margine ai casi Laval e Viking», $L a$ voro e diritto, v. 22., n. ${ }^{\circ}$ 1, 2008, pp. 63-98.

MAESTRO BUELGA, G., «El Tratado de Lisboa y la Constitución económica», Revista de Derecho Constitucional Europeo, n. ${ }^{\circ}$ 9, 2008, pp. 37-68.

MANGAS MARTÍN, A., LIÑÁN NOGUERAS, D. J., Instituciones y De-

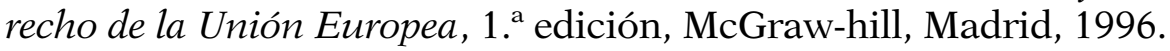

- Instituciones y Derecho de la Unión Europea, 6. ${ }^{a}$ edición, Tecnos, Madrid, 2010.

MANGAS MARTÍN, A., «Introducción. El Compromiso con los derechos fundamentales», en MANGAS MARTÍN, A., (ed.), Carta de los derechos fundamentales de la Unión Europea: comentario artículo por artículo, Fundación BBVA, Bilbao, 2008, pp. 31-75. 
MAESTRO BUELGA, G., «El Tratado de Lisboa y la Constitución económica», Revista de Derecho Constitucional Europeo, n. ${ }^{\circ}$ 9, 2008, pp. 37-68.

MATTERA, A., «El Reglamento n. ${ }^{\circ}$ 2679/98: un instrumento de intervención rápida para salvaguardar la unidad de Mercado Interior», Gaceta Jurídica de la Unión Europea y de la competencia, n. ${ }^{\circ} 204$, 1999, pp. 21-35.

MORTELMANS, K., "The Common Market, the Internal Market and the Single Market, what's in a market?, Common Market Law Review, v. 35 , n. ${ }^{\circ} 1,1998$, pp. 101-136.

OLIVER, P., Free movements of goods in the European Community, Sweet \& Maxwell, Londres, 1996.

PAGANO, E., «Dalla Carta di Nizza alla Carta di Strasburgo dei diritti fondamentali», Diritto Pubblico Comparato ed Europeo, n. ${ }^{\circ}$ 1, 2008, www.dpce.it.

PAGE, A. C., "The Concept of Measures Havign an Effect Equivalent to Quantitatives Restrictions», European Law Review, n. ${ }^{\circ}$ 2, 1977, pp. 105-117.

PARISI, N., «Funzione e ruolo della Carta dei diritti fondamentali dell'Unione europea nel sistema delle fonti alla luce del Trattato di Lisbona», www.estig.ipbeja.pt/ ac_direito/FunzioneCarta_dei_diritti_fondamentali.pdf

PATRUNO, L., "Il Caso Rúffert: la Corte di giustizia CE fa un altro passo avanti nella «via giudiziaria al dumping sociale», www.costituzionalismo.it.

PÉREZ DE LAS HERAS, B., El Mercado Interior Europeo. Las libertades económicas comunitarias: mercancías, personas, servicios y capitales, 2. ${ }^{a}$ edición, Universidad de Deusto, Bilbao, 2008.

POIARES MADURO, M., "Striking the Elusive Balance Between Economic Freedom and Social Rights in the European Union", en ALSTON, P., CASSESE, A., LALUMIÈRE, C., LEUPRECHT, P. (eds.), An EU Human Rights Agenda for the New Millenium, Hart Publishing, Oxford, 1999, pp. 449-472.

POIARES MADURO, M., y AZOULAI, L. (eds.), The past and Future of EU Law: The Classics of EU Law Revisited on the 50th Anniversary of the Rome Treaty, Hart Publishing, Oxford y Portland, 2010. 
RODRÍGUEZ IGLESIAS, G. C., y LIÑÁN NOGUERAS, D. J., (dir.), El Derecho Comunitario Europeo y su aplicación judicial, Civitas, Madrid, 1993.

RODRÍGUEZ-PIÑERO ROYO, M., «Libertades económicas y derechos sociales en la Unión Europea», XX Congreso Nacional Asociación Española de Derecho del Trabajo y de la Seguridad Social, Logroño, mayo de 2009, www.aedtss.com/TERCERA_PONENCIA_MRPR.doc.

ROIG MOLÉS, E., «Continuidad y refundación; deliberación y decisión: el proceso de la Convención y la reforma de los Tratados», en ALBERTI ROVIRA, A. (dir.), El Proyecto de nueva Constitución Europea, Tirant lo blanch,, Valencia, 2004, pp. 17-131.

ROMÁN GONZÁLEZ, E., «Libertades económicas y derechos fundamentales. La doctrina de los Mandatory Requirements en la Jurisprudencia del TJCE», Boletín Mexicano de Derecho Comparado, nueva serie, n. ${ }^{\circ} 127,2010$, pp. 527-543.

ROSSI, L. S., y CURSON, S. J., «What «Rule of Reason» for the EU Internal Market?», Studi sulla inegrazione europea, 2008, n. ${ }^{\circ} 2$, pp. 295-309.

SARRIÓN ESTEVE, J., «Los conflictos entre libertades económicas y derechos fundamentales en la jurisprudencia del Tribunal de Justicia de la Unión Europea», Revista de Derecho Político, n. ${ }^{\circ} 81$, 2011, pp. 279-412.

- «El nuevo horizonte constitucional para la Unión Europea: a propósito de la entrada en vigor del Tratado de Lisboa y la Carta de Derechos Fundamentales», CEFLegal: revista práctica de derecho, n. ${ }^{\circ} 121,2011$, pp. 53-102.

- «La libre circulación de personas como dereho fundamental de los ciudadanos en la Unión Europea», Panorama Social, n. ${ }^{\circ}$ 17, 2013, pp. 33-40.

TENORIO SÁNCHEZ, P. J., «Diálogo entre tribunales y protección de los derechos fundamentales en el ámbito europeo", Revista General de Derecho Europeo, n. ${ }^{\circ}$ 31, 2013.

TRUYOL SERRA, A., La integración europea. Análisis histórico-documental con textos y documentos [I Génesis y desarrollo de la Comunidad Europea (1951-1979)], Tecnos, Madrid 1999.

WYATT, D., «Article 30 and Non-Discriminatory Trade restrictions», European Law Review, n. ${ }^{\circ}$ 6, 1981, pp. 185-193. 
WEILER, J. H. H., «The Constitution of the common Market Place: Text and Context in the Evoluiton of the Free Movement of Goods», en CRAIG, P., DE BÚRCA, G. (eds.), The Evolution of EU Law, Oxford University Press, Oxford,1999, pp. 349-376. 
